\title{
Análise da recomposição do sistema de distribuição do Amapá após a perturbação que provocou o blecaute em 3 de novembro 2020
}

\author{
Analysis of the Amapá distribution system recomposition after the disturbance that caused the \\ blackout on November 3rd, 2020 \\ Análisis de la recomposición del sistema de distribución de Amapá después de la perturbación que
}

causó el apagón del 3 de noviembre de 2020

Igor Oeiras Cordeiro

ORCID: https://orcid.org/0000-0001-6040-8620 Universidade Federal do Amapá, Brasil E-mail: tencordeiro34bis@outlook.com

Patrick Nascimento Matos

ORCID: https://orcid.org/0000-0003-2535-8773 Universidade Federal do Amapá, Brasil

E-mail: patricknsmatos@gmail.com

Amanda Thais dos Reis Fernandes

ORCID: https://orcid.org/0000-0002-3388-9681 Universidade Federal do Amapá, Brasil

E-mail: fernandes@ieee.org

Paulo Breno da Silva Grott

ORCID: https://orcid.org/0000-0001-8363-9771 Universidade Federal do Amapá, Brasil E-mail: grott@ieee.org

Marcelo Ricardo Souza Siqueira ORCID: https://orcid.org/0000-0002-1153-2251 Universidade Federal do Amapá, Brasil E-mail: marcelo.siqueira@unifap.br

Werbeston Douglas de Oliveira ORCID: https://orcid.org/0000-0002-4566-6290 Universidade Federal do Amapá, Brasil E-mail: wdoliveira@unifap.br

\begin{abstract}
Resumo
Este trabalho propõe uma análise quantitativa e qualitativa acerca do blecaute ocorrido no Sistema Amapá em 3 de novembro de 2020. Bem como, o processo de recomposição e suas características operacionais, avaliando o tempo de recomposição e a quantidade de carga atendida. Além da análise do ocorrido, o estudo busca avaliar a recomposição da fase fluente e coordenada do sistema elétrico do Amapá, verificar as ações tomadas pelo Operador Nacional do Sistema Elétrico - ONS, UHE Coaracy Nunes e Companhia de Eletricidade do Amapá - CEA para tomada de carga no início do blecaute até o reestabelecimento total das cargas do Amapá, verificar os critérios adotados pela CEA para tomada de carga durante as fases de recomposição, discorrer sobre a indisponibilidades de equipamentos nas Subestações da CEA durante o processo de recomposição fluente e tratar sobre o desempenho e impactos do Esquema Regional de Alívio de Carga - ERAC durante o processo de recomposição fluente por meio da UHE Coaracy Nunes no dia 04 de novembro de 2020, uma vez que foi observado que havendo a disponibilidade do transformador 2 (reserva) de 150 MVA na SE Macapá e da Usina Geradora 1 - UG1 AMAPÁ na UHE Coaracy Nunes, além da atuação correta do ERAC nas subestações da distribuidora CEA, os impactos poderiam ser mitigados, especialmente quanto a potência disponível e quanto aos desligamentos das Unidades Geradoras em Coaracy Nunes por subfrequência, tornando o processo de recomposição fluente mais estável e afetando em escala menor a sociedade amapaense.
\end{abstract}

Palavras-chave: Recomposição; Cargas; ERAC; Blecaute.

\section{Abstract}

This paper proposes a quantitative and qualitative analysis about the blackout that occurred in Amapá System on November 3, 2020 and an approach to the recomposition process and its operational characteristics mentioning points for improvement either in the time of this recomposition and the amount of load served. Besides the analysis of what happened, the study seeks to evaluate the recomposition of the fluent and coordinated phase of Amapá's electric system, 
to verify the actions taken by the National Electric System Operator - ONS, UHE Coaracy Nunes and Companhia de Eletricidade do Amapá - CEA for load taking at the beginning of the blackout until the total reestablishment of Amapá's loads, To verify the criteria adopted by the CEA for load shedding during the recovery phases, discuss the unavailability of equipment at the CEA substations during the fluent recovery process and address the performance and impacts of the Regional Load Relief Scheme - ERAC during the fluent recovery process through the Coaracy Nunes HPP on November 4th, 2020, since it was observed that with the availability of transformer 2 (reserve) of 150 MVA in SE Macapá and of Generating Plant 1 - UG1 AMAPÁ in UHE Coaracy Nunes, in addition to the correct performance of ERAC in the substations of the distributor CEA, the impacts could be mitigated, especially regarding the available power and regarding the shutdowns of the Generating Units in Coaracy Nunes by underfrequency, making the fluent recomposition process more stable and affecting in a smaller scale the Amapaense society.

Keywords: Recomposition; Loads; ERAC; Blackout.

\begin{abstract}
Resumen
Este trabajo propone un análisis cuantitativo y cualitativo sobre el apagón ocurrido en el Sistema Amapá el día 3 de noviembre de 2020 y una aproximación al proceso de recomposición y sus características operativas mencionando puntos de mejora tanto en el tiempo de esta recomposición como en la cantidad de carga atendida. Además del análisis de lo ocurrido, el estudio busca evaluar la recomposición de la fase fluida y coordinada del sistema eléctrico de Amapá, verificar las acciones realizadas por el Operador Nacional del Sistema Eléctrico - ONS, la UHE Coaracy Nunes y la Compañía de Electricidad de Amapá - CEA para la toma de carga al inicio del apagón hasta el restablecimiento total de las cargas de Amapá, verificar los criterios adoptados por la CEA para tomar la carga durante las fases de recuperación, discutir sobre la indisponibilidad de equipos en las subestaciones de la CEA durante el proceso de recuperación fluida y abordar el desempeño y los impactos del Esquema Regional de Alivio de Carga - ERAC durante el proceso de recuperación fluida a través de la C.P. Coaracy Nunes el 4 de noviembre de 2020, ya que se observó que con la disponibilidad del transformador 2 (reserva) de 150 MVA en la SE Macapá y de la Usina de Generación 1 - UG1 AMAPÁ en la UHE Coaracy Nunes, además de la correcta actuación del ERAC en las subestaciones de la distribuidora CEA, los impactos podrían ser mitigados, especialmente en lo que se refiere a la potencia disponible y en lo que se refiere a las paradas de las Unidades Generadoras en Coaracy Nunes por subfrecuencia, haciendo más estable el proceso de recomposición fluida y afectando a la sociedad amapense en menor escala.
\end{abstract}

Palabras clave: Recomposición; Cargas; ERAC; Apagón.

\title{
1. Introdução
}

A operação dos Sistemas Elétricos de Potência (SEP) necessita ser segura, com tomadas de decisões rápidas, confiáveis e de fácil execução. Contudo, a crescente demanda por energia elétrica e dificuldades na expansão da rede, tendem a levar o SEP a operar cada vez mais próximo dos seus limites operacionais por longos períodos, sejam eles, limites de carregamento de linhas, geradores ou transformadores (Pardauil, et al., 2020). É importante salientar, que estudos de segurança de SEP levam em conta uma lista pré-determinada de contingências. Contudo, ocasionalmente ocorrem situações inesperadas ou pouco prováveis, o que leva a situações de blecautes (Oliveira, et al., 2017; Nogueira, et al., 2020).

O blecaute do sistema elétrico do Amapá ocorrido em 3 de novembro de 2020 que ocasionou o ilhamento de 13 dos 16 municípios do estado, atingindo, segundo o Ministério de Minas e Energia, cerca de 730 mil pessoas, teve início após um curtocircuito na fase B do Transformador 150 MVA - TR1 230/69/13,8 kV, desencadeando, neste equipamento, um incêndio que ocasionou perda total do TR1 e desligou o Transformador 150 MVA - TR3 230/69/13,8 kV por sobrecarga, deixando o sistema em Estado Restaurativo por 22 dias (ONS, 2020).

Após a suspensão no suprimento de energia, só foi possível no dia subsequente a perturbação proceder com processo de recomposição fluente de apenas 15 MW para atender as demandas prioritárias do estado, em especial, os serviços de saúde em virtude do momento de extrema dificuldade vivido por todo planeta por conta da pandemia de COVID-19, uma vez que os hospitais e UBS's estavam em constantes utilização para tratamento de pacientes infectados pela COVID-19 e que o retorno do TR3 foi possível somente dia 7 de novembro, restabelecendo patamares entre 60 a $70 \%$ da carga de Macapá dando início ao rodízio a cada 6 horas entre os alimentadores para o fornecimento de energia aos atingidos pelo blecaute (ONS, 2020; CEA, 2020; G1 Amapá, 2020).

Neste enredo, serviços essenciais como fornecimento de água e telecomunicações ficaram suspensos total ou 
parcialmente e a população do estado enfrentou quanto ao armazenamento de alimentos perecíveis, abastecimento de veículos e demais necessidades básicas, gerando uma onda de protestos, especialmente na capital, e diversas filas por itens primários como água potável (G1 Amapá, 2020).

Por este ângulo, observamos que os impactos impostos à sociedade pelo corte do suprimento de energia foram devastadores e que melhorias durante a recomposição do sistema poderiam mitigar alguns pontos desse impacto, seja na quantidade de consumidores atendidos antes ou durante o rodízio, mesmo considerando as cargas prioritárias e também no tempo elevado durante a recomposição fluente do sistema, situações essas provavelmente ocasionadas por erros no Esquema Regional de Alívio de Carga - ERAC, tendo em vista os diversos desligamentos das Unidades Geradoras da UHE Coaracy Nunes por subfrequência, indicando problemas com tomada de carga elevada e sem cortes seletivos, justificando, portanto, uma análise pormenorizada e adequada, aspirando proporcionar resultados melhores à sociedade, seja na diminuição do tempo de recomposição fluente e/ou no fornecimento de energia à maior parte possível da população amapaense.

\section{Referencial Teórico}

\subsection{O Sistema Elétrico de Potência}

A estrutura de um sistema elétrico de potência compreende os sistemas de geração, transmissão e distribuição, cobrindo uma grande área geográfica. O sistema de geração possui a atribuição de conversão de energia de alguma natureza (hidráulica, térmica, solar, eólica etc.) em energia elétrica. Essa energia é transportada através do sistema de transmissão dos centros de produção aos centros de consumo. Por fim, a distribuição que direciona a energia recebida da rede de transmissão para os grandes, médios e pequenos consumidores caracterizados como residências, comércios e indústrias (Kagan et al.; 2010; ABRADEE, 2018; Vaz, 2017), conforme exemplificado na Figura 1.

Figura 1 - Estrutura de um Sistema Elétrico de Potência.

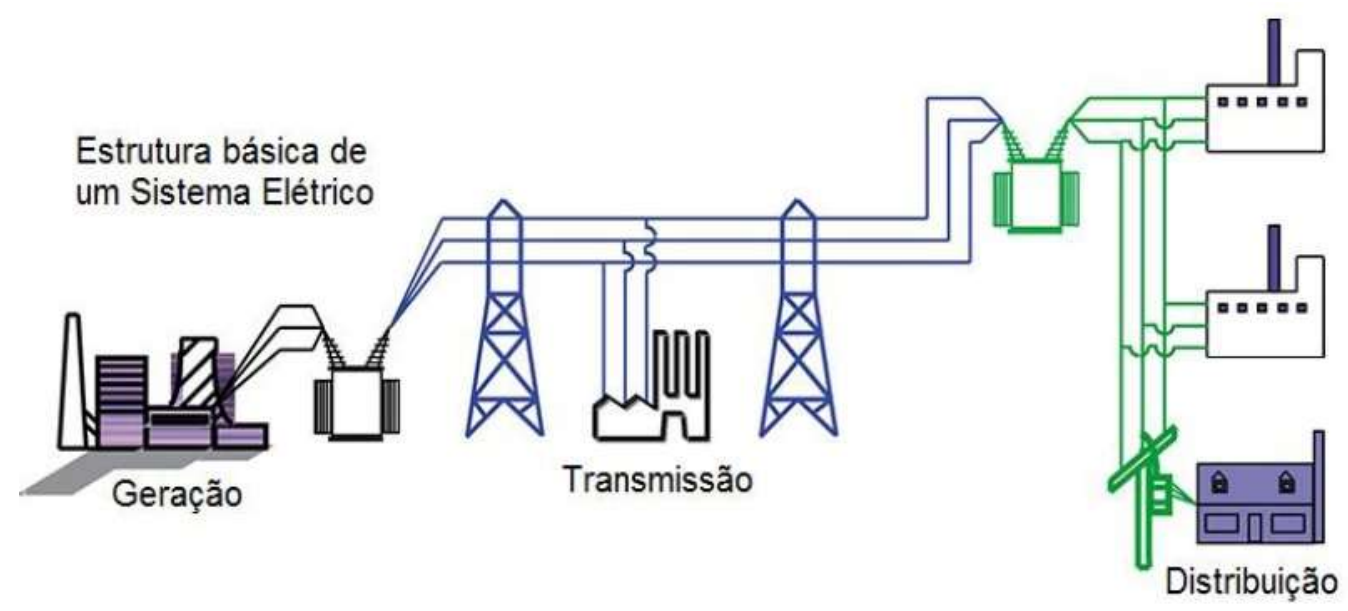

Fonte: Adaptado pelos Autors (Idaho, 2016).

Este é o modelo estrutural do sistema elétrico de potência brasileiro. A infraestrutura do segmento energético implantado atualmente é estabelecida pelo Sistema Interligado Nacional (SIN), constituído por quatros subsistemas: Sul, Sudeste/CentroOeste, Nordeste e a maior parte da região Norte. Assim, a energia que é distribuída aos centros de consumo é conectada a uma grande rede nacional permitindo transferência de energia entre os subsistemas (Monticelli \& Garcia, 2011). Essa configuração permite ser feito o melhor aproveitamento das fontes de energia, com o menor custo operacional e aumento da confiabilidade do sistema. 
Ainda também, há diversos sistemas de porte menor, que não estão conectados ao SIN, concentrados principalmente na região Amazônica, no Norte do país. Isto ocorre porque as características geográficas da região, composta por floresta densa e heterogênea, além de rios caudalosos e extensos, dificultaram a construção de linhas de transmissão de grande extensão que permitissem a conexão ao SIN (Alves, 2014; ANEEL, 2016).

\subsection{O Sistema de Distribuição de Energia Elétrica}

O sistema de distribuição é o estágio final da transferência de potência até o consumidor. A tensão primária em rede pública opera entre $34,5 \mathrm{KV}$ a $13,8 \mathrm{KV}$. Pequenos consumidores industriais são atendidos através da distribuição primária, enquanto os consumidores residenciais e comerciais operam nas tensões de 127/220 V ou 220/380 V, chamada de distribuição secundária (Walantus, 2014; Souza, 2008; ABRADEE 2021).

Um diagrama unifilar de um sistema elétrico de potência composto por geração (três usinas), um conjunto de linhas de transmissão, rede de subtransmissão, rede primária e três redes de distribuição secundárias conforme demonstrado na Figura 2 (Walantus, 2014; Souza, 2008).

Figura 2 - Diagrama Unifilar SEP.

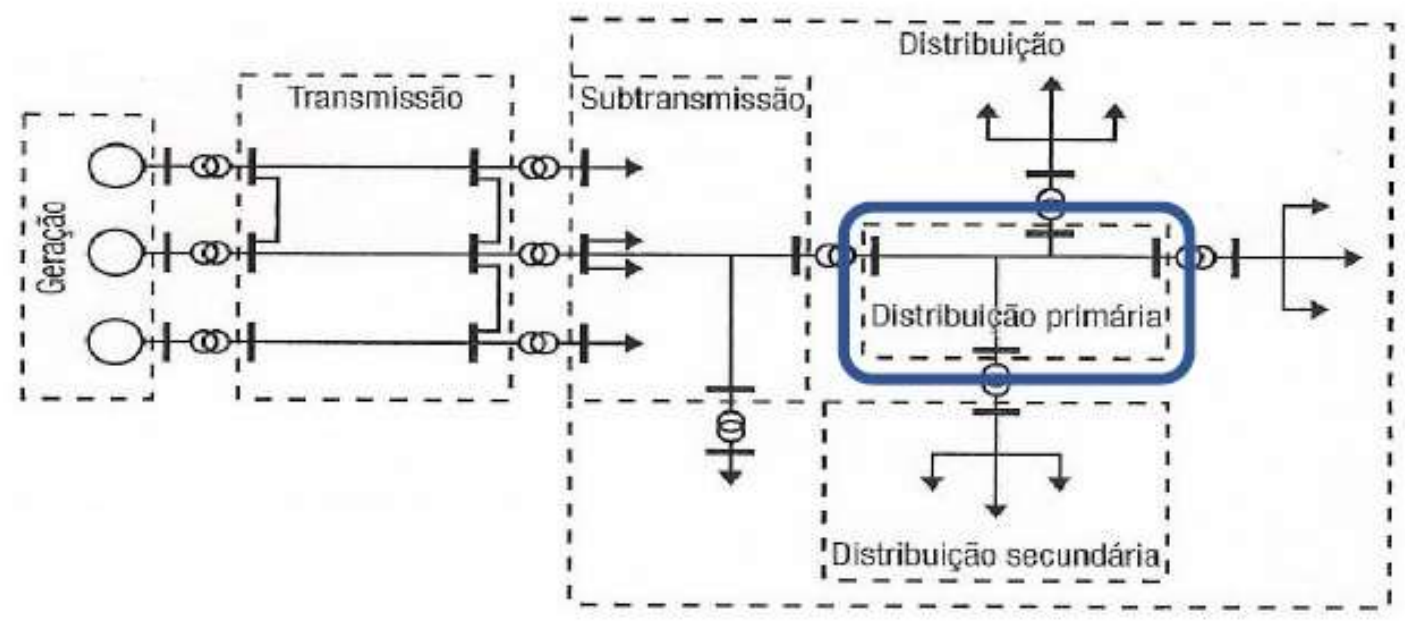

Fonte: Kagan et al. (2010).

As redes de distribuição primárias, também são denominadas de média tensão, sua origem é proveniente das subestações de distribuição. Em geral, a transferência dessa energia é realizada pelos chamados alimentadores. Essas redes possuem um tronco principal dos quais derivam ramais definidos pela presença de elementos de proteção, como chaves fusíveis e seccionadoras em posições normalmente fechadas (NF), a fim de garantir isolamento de bloco de cargas. No caso das chaves serem normalmente abertas (NA), elas funcionam como recursos de operação em caso de perturbações na rede elétrica. A rede de distribuição secundária, também denominada de baixa tensão, tem sua origem no processo de transformação da rede primária proveniente dos transformadores de distribuição existente atendendo diretamente com energia efetiva o consumidor (Podeleski, 2017; Souza, 2008, Pestana, 2009). 


\subsection{Estado da Rede Elétrica}

A operação da rede elétrica é classificada em três estados sendo denominados em: Normal, Emergência e Restaurativo. O estado normal é caracterizado pelo fornecimento de energia sem a violação dos limites operacionais de atendimento de demandas. O estado de emergência é caracterizado pelo fornecimento de energia com a violação de alguns limites operacionais. E por fim, o estado restaurativo é caracterizado por interrupção no serviço (Podeleski, 2017; Mota, 2005).

O sistema de distribuição opera no estado normal até que um evento inesperado aconteça, podendo levar ao estado de emergência. Nesse estado, as falhas transitórias estão sendo solucionadas pelos elementos de proteção da rede, em caso de falhas permanentes, o sistema entra no estado restaurativo no qual apenas ações corretivas podem restabelecer o fornecimento de energia (Podeleski, 2017; Mota, 2005). A Figura 3 demonstra as relações entre os modos de operação e suas respectivas nomenclaturas (Oliveira, 2017). Quando a rede atinge o estado restaurativo são tomadas as ações de recomposição do sistema elétrico para reestabelecer o fornecimento nas condições normais operativas (Podeleski, 2017; Mota, 2005).

Figura 3 - relação de estado de operação de sistema elétrico.

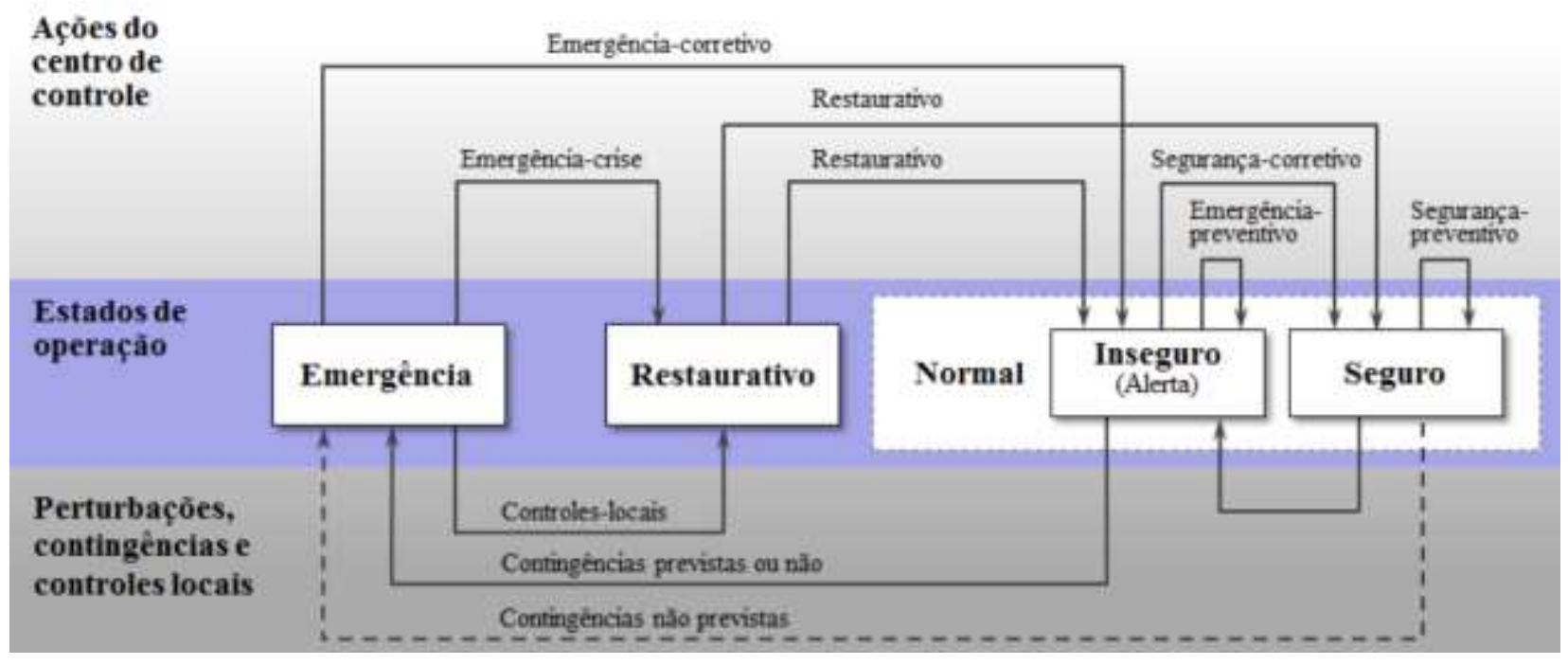

Fonte: Oliveira (2017).

\subsection{Recomposição}

Após a ocorrência de uma perturbação no sistema elétrico que tenha como resultado a interrupção do serviço de maneira total ou parcial, colocando assim o sistema no estado restaurativo, são iniciadas as ações de recomposição que estão focadas em reestabelecer o fornecimento de energia através de transferência de carga a áreas isoladas da região afetada. É realizada mediante controle de elementos que operam em diferentes estados (aberto e fechado), e de acordo com as manobras executadas ocorre alteração no estado de carga da rede de distribuição. As alterações para recomposição do sistema, mediante alguma contingência ou blecaute necessitam observar diversos parâmetros. Uma vez que o SEP possui limites operacionais que podem impedir que novas configurações sejam suportadas (Mota, 2005; Pestana, 2009, Podeleski, 2017).

As falhas que acometem o sistema elétrico por ocasião de uma perturbação são de 2 (dois) tipos, denominada transitório ou permanente (Borges et al., 2012). As falhas transitórias são resultado de mal desempenho de algum elemento de rede que causem danos ou perturbação ao sistema oriunda de curto-circuito. Neste sentido, ocorre a atuação de equipamentos de proteção removendo a falha imediatamente a fim de evitar danos ao circuito elétrico (Oh \& Kim,2002). Por conta da sua natureza temporária não há necessidade de remoção da falha seguindo apenas com a reenergização do sistema (Souza, 2008). As falhas 
permanentes são aquelas que mesmo após atuação do equipamento de proteção necessita de ações corretivas para reestabelecer o fornecimento de energia (Podeleski, 2017).

Portanto, as ações de recomposição estão relacionadas com estado de falha do sistema elétrico, após atuação dos elementos de proteção e isolamento da área com defeito, adotando procedimentos nos quais se avaliam a capacidade da rede em suportar transferências de cargas das áreas afetadas por meio de outros ramos mantendo a topologia radial. As estratégias de recomposição devem observar o atendimento que ocasionou a interrupção, buscando atender uma rede específica e o conjunto de atribuições analisando características estruturais, recursos de rede disponíveis, topologia e carga do sistema. A recomposição do sistema elétrico interligado após o blecaute é dividida em duas fases denominadas fluente e coordenada. A fase fluente trata de um conjunto de áreas de auto restabelecimento, constituído de usinas, linhas de transmissão e equipamentos em que a geração é compatível com a carga prioritária mínima a ser atendida, sendo que a cargas prioritárias são definidas pelo agente de distribuição (Podeleski, 2017; Mota, 2005; Pestana, 2009). Na fase coordenada, o centro do ONS coordena as demais interligações restaurando o sistema em condições normais de operação (Modulo 10, submodulo 10.11 ONS).

\subsection{Perturbação na Subestação Macapá}

A Subestação denominada Macapá (SE Macapá) é a responsável pela transformação da energia oriunda da fonte de suprimento proveniente do SIN, sendo composta por 3 (três) transformadores trifásicos de capacidade de 150 MVA (ONS, 2020).

A perturbação na Subestação Rebaixadora Macapá com nível de tensão em 230/69/13.8 kV que gerou o apagão energético no estado do Amapá no fatídico dia 03 de novembro de 2020, por volta de 20h48min (horário de Brasília), teve início com o desligamento dos transformadores TR1 de 230/69/13,8 kV da referida subestação, tendo, na sequência, ocorrido o desligamento da UHE Coaracy Nunes e do Sistema Amapá atendido pela referida subestação (ONS, 2020).

Figura 4 - Incêndio do TR1 da SE Macapá.

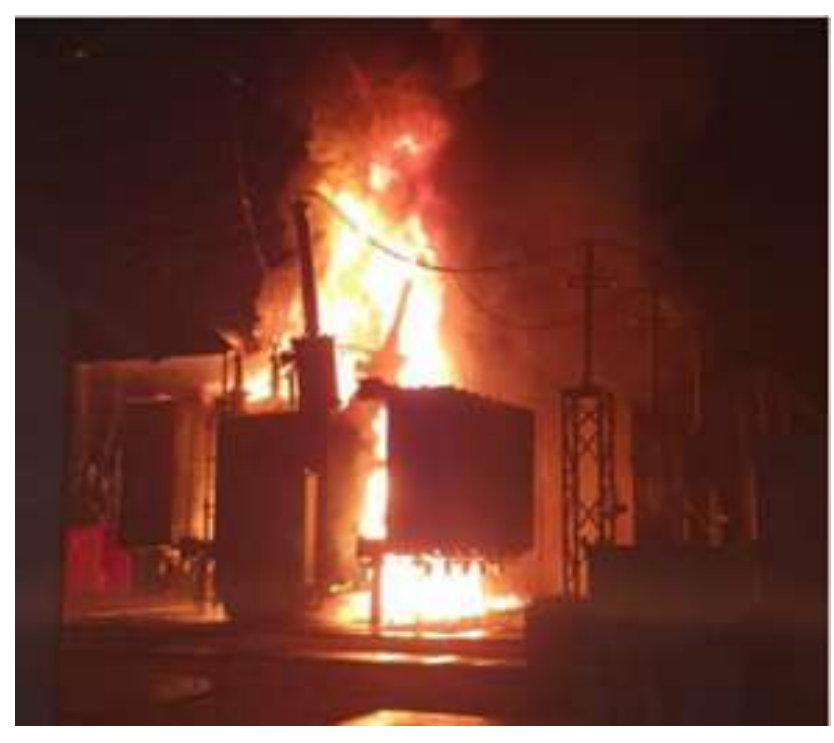

Fonte: Relatório ONS (2020).

A perturbação que ocasionou o corte no suprimento de potência para 13 (treze) das 16 (dezesseis) cidades do Estado do Amapá, iniciou-se com um curto-circuito na fase B do lado primário do Transformador TR1 230/69/13,8 kV provocando um incêndio no referido Trafo e levando a perda total do equipamento, além de motivar, por consequência, o desligamento automático do transformador TR3 230/69/13,8 kV, causado por sobrecarga, tendo em vista que o suprimento de $242 \mathrm{MW}$ de potência ficou sendo atendido somente pelo transformador TR3 de 150 MVA e UHE Coaracy Nunes (ONS, 2020). 
O desligamento do TR3 teve como principal consequência o ilhamento de toda a carga do estado alimentada pelo transformador da SE Macapá e a UHE Coaracy Nunes, cabendo a ressalva de que a subestação onde ocorreu a perturbação possui como configuração três transformadores trifásicos de 150 MVA, estando, no entanto, o transformador TR2 230/69/13,8 kV indisponível em decorrência da explosão da bucha da fase A de 69 kV desde o final de 2019 (ONS, 2020).

A perturbação ocasionou a suspensão do suprimento de energia de cerca de $95 \%$ do total das cargas do estado do Amapá, sendo realizadas até, por volta de $06 \mathrm{~h} 43 \mathrm{~min}$ do dia subsequente, 6 (seis) tentativas sem sucesso de recomposição fluente da área pela UHE Coaracy Nunes, com reestabelecimento inicial em patamares de 4 a $8 \mathrm{MW}$, tendo como causa do insucesso na recomposição a atuação da proteção por subfrequência da referida UHE (ONS, 2020).

Entre os horários de $06 \mathrm{~h} 43$ min e 22h10min do dia 4 de novembro de 2020, houveram sucessivas tentativas de retomada de carga por parte da Companhia de Eletricidade do Amapá (CEA) e estabilização do sistema de distribuição com suprimento de carga em patamares de $35 \mathrm{MW}$ a 38 MW pelo fornecimento de potência da UHE Coaracy Nunes, porém o sistema não atingia a estabilidade e por diversas vezes ocorria a interrupção do suprimento, levando, por consequência, o ONS a tomar a decisão junto a CEA de limitar as cargas atendidas pela usina em 30 MW (ONS, 2020).

\subsection{Esquema Regional de Alívio de Carga - ERAC}

Em certos casos de contingência elétrica, perdas de grandes blocos de geração podem culminar com a diminuição rápida da velocidade nas demais máquinas desse sistema, uma vez que reguladores de velocidade não respondem com velocidade suficiente para restabelecimento do balanço entre o torque mecânico e elétrico nos sistemas de geração. Após o blecaute em 1965 ocorrido nos Estados Unidos, o North American Electric Council (NERC) propôs um sistema de contenção baseado em controle por subfrequência. Assim, sua filosofia de atuação baseia-se no restabelecimento da frequência aos patamares compatíveis com as unidades geradoras em operação, retirando, assim, a possibilidade de desligamentos em cascata, que resultam em perdas de grandes blocos de carga, devido aos baixos valores de frequência (Brolin, 2010).

Segundo o Módulo 5 - Submódulo 5.12 do Manual de Procedimentos da Operação do ONS, o Esquema Regional de Alívio de Carga - ERAC, nada mais é do que um Sistema Especial de Proteção que possui como finalidade precípua realizar cortes seletivos e automáticos de carga por subfrequência e/ou taxa de variação de frequência decorrentes de perda de grandes blocos de geração, aplicando-se, inclusive, a toda a rede de operação do SIN (ONS, 2021).

O ERAC efetua o corte de carga por meio de relés de taxa de variação de frequência no tempo $(\Delta \mathrm{F} / \Delta \mathrm{T})$, medida em uma janela de frequência, e/ou por meio de relés de frequência absoluta, que atuam desligando automaticamente as cargas previamente estabelecidas, sempre que forem atingidos os valores de taxa de frequência, frequência absoluta e temporização caso exista (ONS, 2021).

\section{Metodologia}

O presente trabalho adota uma metodologia de natureza explicativa, onde se pretende verificar o processo de recomposição aplicado durante o estado restaurativo ocorrido no Amapá em decorrência do blecaute do dia 3 de novembro de 2020 ocorrido na Subestação Macapá para avaliar o desempenho das ações realizadas pelo ONS e agentes. Observando pontos de melhorias, com o intuito de padronizar procedimentos e melhorar o desempenho dos agentes frente a eventos similares. Portanto trata-se de um estudo de caráter quantitativo e qualitativo, com isso realizou-se pesquisa bibliográfica a fim de levantar as referências e a análise de dados obtidos, especialmente junto a distribuidora de energia do estado e do Relatório de Análise de Perturbação - RAP do ONS. 
O objetivo das análises de perturbações, de maneira geral, é fornecer subsídios para a determinação das responsabilidades quanto à origem, às causas do evento e às consequências geradas para o sistema, além de identificar as responsabilidades dos agentes envolvidos nas perturbações em instalações do acessante ou da distribuidora para mitigar futuras ocorrências semelhantes.

Com o intuito de obter os resultados esperados, identificando os possíveis erros durante o processo de recomposição e os pontos de melhorias do sistema Amapá, especialmente quanto aos procedimentos da distribuidora CEA. O trabalho menciona as ações descritas no RAP e relatórios disponibilizados pela CEA conforme a sequência abaixo:

1. A recomposição da fase fluente e coordenada do sistema elétrico do Amapá;

2. Ações tomadas pelo ONS, UHE Coaracy Nunes e CEA para tomada de carga no início do blecaute até o reestabelecimento total das cargas do Amapá;

3. Os critérios adotados pela CEA para tomada de carga durante a fase de recomposição fluente e coordenada;

4. A indisponibilidade de equipamentos nas Subestações da CEA durante o processo de recomposição fluente; e

5. O desempenho e impactos do Esquema Regional de Alívio de Carga - ERAC durante o processo de recomposição fluente por meio da UHE Coaracy Nunes no dia 04 de novembro de 2020.

Por fim, ao analisar a recomposição do sistema aponta-se medidas e estudos futuros que visam estabelecer critérios que minimizem impactos no sistema elétrico proveniente da tomada de carga.

\section{Resultados e Discussões}

\subsection{Ações do ONS e Agentes}

A perturbação que ocorreu no dia 3 de novembro de 2020 por volta das $20 \mathrm{~h} 48$ min teve início com desligamento dos transformadores TR1 e TR3 de potência de 150 MVA localizados na SE Macapá de propriedade da empresa LMTE/ISOLUX e na sequência deste evento houve um desligamento também da UHE Coaracy Nunes de propriedade da Eletronorte neste sentido ocasionando a perda de 95\% da carga do sistema Amapá (ONS, 2020).

Instantes antes do evento de blecaute o sistema Amapá operava com um montante total de carga de 256 MW, sendo que 242 MW estava sendo atendido pela SE Macapá e UHE Coaracy Nunes. Apenas o município de Oiapoque, que não está integrado ao SIN, e Laranjal do Jari e Vitoria do Jari que são atendidos pela SE laranjal não foram afetados.

Figura 5 - Diagrama Elétrico Simplificado do Sistema Amapá.

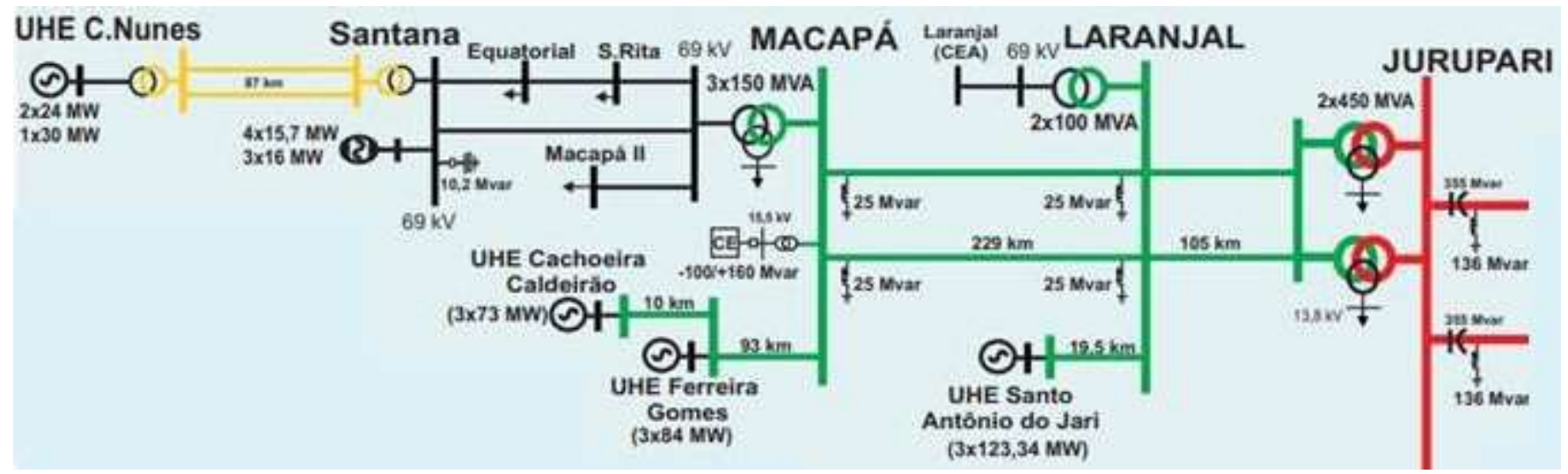

Fonte: Adaptado pelos autors (ONS, 2020).

O diagrama mostrado na Figura 5 delimita a forma de atendimento das cargas do sistema Amapá. O suprimento de 
carga dos 13 (treze) municípios são realizados pela SE Macapá e UHE Coaracy Nunes sendo que sua interligação ao SIN ocorre por uma linha de transmissão em circuito duplo de $230 \mathrm{KV}$ proveniente da SE Jurupari 500/230 KV. A UHE Coaracy Nunes é composta por 3 (três) unidade geradoras totalizando $78 \mathrm{MW}$ de potência instalada, sendo que no dia do evento a unidade geradora 1 (UG1) estava indisponível para operação, sendo que após o início da perturbação a Unidade Geradora (UG2) da UHE Coaracy Nunes sofre um desligamento por atuação de subfrequência ajustada em $56 \mathrm{HZ}$ com temporização de 2s, logo em seguida, cerca de 11s ocorre o desligamento da UG3 da UHE Coaracy Nunes pela atuação da função de sobrecorrente com controle por tensão (51C) (ONS, 2020).

Diante do cenário apresentado com desligamento das 2 (duas) fontes supridoras, o ONS em conjunto com os agentes iniciam as ações de recomposição do sistema Amapá a fim retomar as cargas.

Na SE Macapá por volta das 22h55min houve uma ação de normalização do TR3, o qual foi energizado a vazio, contudo sofreu um curto-circuito interno na fase B para o terra do lado de $69 \mathrm{KV}$ provocando um novo desligamento do equipamento e deixando-o indisponível. Em virtude da indisponibilidade de transformadores na SE Macapá, o atendimento das cargas ocorreu apenas pela UHE Coaracy Nunes, que iniciou a fase de recomposição fluente através de 1 (uma) unidade geradora com a função de efetuar o controle de frequência da área, somente após a energização do primeiro circuito da LT 138 KV Coaracy Nunes/ SE Santana e a tomada de carga inicial que foi permitida a sincronização da outra unidade geradora. Todavia, obteve dificuldade na sincronização das unidades geradoras no processo de tomada de carga e foi observado pela ONS diversos desligamento causados principalmente por variações na frequência. Somente no dia 4/11/2021 por volta das $6 \mathrm{~h} 43 \mathrm{~min}$ foi iniciada as ações de recomposição das cargas pela Companhia de Eletricidade do Amapá. O Quadro 1 mostra a sequência das ações de recomposição (ONS, 2020).

Quadro 1 - sequência de normalização do sistema Amapá.

\begin{tabular}{|c|c|c|}
\hline \multicolumn{3}{|r|}{ Sequência de normalização } \\
\hline Data/Hora & Instalação & Descrição do evento ou observações \\
\hline $\begin{array}{l}03 / 11 / 2021 \\
21 \mathrm{~h} 32\end{array}$ & SE Laranjal / SE Macapá & Ligada a LT 230 kV Laranjal / Macapá C1 AP \\
\hline $\begin{array}{l}03 / 11 / 2021 \\
22 \mathrm{~h} 54\end{array}$ & SE Macapá & Ligado o TR3 230/69 kV da SE Macapá AP \\
\hline $\begin{array}{l}03 / 11 / 2021 \\
22 \mathrm{~h} 55\end{array}$ & SE Macapá & Desligamento automático do TR3 230/69 kV da SE Macapá AP \\
\hline $\begin{array}{l}03 / 11 / 2021 \\
23 \mathrm{~h} 59\end{array}$ & UHE Coaracy Nunes & Ligada a UG02 da UHE Coaracy Nunes (novo desligamento automático 04/11/20 00h23) \\
\hline $\begin{array}{c}04 / 11 / 20 \\
00 \mathrm{~h} 04\end{array}$ & SE Santana & Energizada a barra $138 \mathrm{kV}$ da SE Santana \\
\hline $\begin{array}{c}04 / 11 / 20 \\
00 \mathrm{~h} 38\end{array}$ & UHE Coaracy Nunes & Ligada a UG02 da UHE Coaracy Nunes (novo desligamento automático 01h09) \\
\hline $\begin{array}{c}04 / 11 / 20 \\
01 \mathrm{~h} 35 \\
\end{array}$ & UHE Coaracy Nunes & Ligada a UG02 da UHE Coaracy Nunes (novo desligamento automático 03h09) \\
\hline $\begin{array}{c}04 / 11 / 20 \\
01 \mathrm{~h} 52 \\
\end{array}$ & UHE Coaracy Nunes & Sincronizada a UG03 da UHE Coaracy Nunes (novo desligamento automático 02h10) \\
\hline $\begin{array}{c}04 / 11 / 20 \\
04 \mathrm{~h} 33 \\
\end{array}$ & UHE Coaracy Nunes & Ligada a UG03 da UHE Coaracy Nunes (novo desligamento automático 04h54). \\
\hline $\begin{array}{c}04 / 11 / 20 \\
05 \mathrm{~h} 06\end{array}$ & UHE Coaracy Nunes & Ligada a UG02 da UHE Coaracy Nunes (novo desligamento automático 06h03) \\
\hline $\begin{array}{c}04 / 11 / 20 \\
06 \mathrm{~h} 09\end{array}$ & UHE Coaracy Nunes & Ligada a UG02 da UHE Coaracy Nunes (novo desligamento automático 11h50) \\
\hline $\begin{array}{c}04 / 11 / 20 \\
06 h 09\end{array}$ & UHE Coaracy Nunes & $\begin{array}{l}\text { Sincronizada a UG03 da UHE Coaracy Nunes (novo desligamento automático 11h50). Às } \\
\text { 06h43 foi iniciada a recomposição das cargas da CEA pela UHE Coaracy Nunes atingindo } \\
\text { um montante de } 38 \text { MW às } 11 \mathrm{~h} 43 \text {. }\end{array}$ \\
\hline $\begin{array}{c}04 / 11 / 20 \\
11 \mathrm{~h} 50 \\
\end{array}$ & UHE Coaracy Nunes & $\begin{array}{l}\text { Desligamento automático das UG02 e UG03 da UHE Coaracy Nunes interrompendo } 38 \text { MW } \\
\text { de cargas restabelecidas até o horário. }\end{array}$ \\
\hline $\begin{array}{c}04 / 11 / 20 \\
13 \mathrm{~h} 00\end{array}$ & UHE Coaracy Nunes & Ligada a UG02 da UHE Coaracy Nunes \\
\hline
\end{tabular}




\begin{tabular}{|c|c|c|}
\hline $\begin{array}{c}04 / 11 / 20 \\
13 \mathrm{~h} 25\end{array}$ & UHE Coaracy Nunes & $\begin{array}{c}\text { Sincronizada a UG03 da UHE Coaracy Nunes Às 13h26 iniciada nova recomposição das } \\
\text { cargas da CEA pela UHE Coaracy Nunes, atingindo patamares de 35 MW, seguidos de } \\
\text { novos desligamentos da UHE Coaracy Nunes interrompendo as cargas restabelecidas. }\end{array}$ \\
\hline $\begin{array}{c}04 / 11 / 20 \\
14 \mathrm{~h} 46\end{array}$ & UHE Coaracy Nunes & Desligamento da UG03 e UG2 por subfrequência. \\
\hline $\begin{array}{c}04 / 11 / 20 \\
18 \mathrm{~h} 29\end{array}$ & UHE Coaracy Nunes & $\begin{array}{c}\text { Desligamento da UG02 e UG03, sendo que na UG03 houve atuação de proteção de } \\
\text { sobrefrequência e UG02 houve atuação de proteção de subfrequência. }\end{array}$ \\
\hline
\end{tabular}

Fonte: Adaptado pelos autores (ONS,2020).

No decorrer do processo da recomposição do sistema, considerando a tomada de carga pela Companhia de Eletricidade do Amapá no dia 4/11/2020, foi observado pelo ONS em 3 (três) eventos que provocaram desligamento por proteção de frequência das UG2 e UG3 da UHE Coaracy Nunes, conforme descrito na tabela 1. O ONS indica que a causa provável dos desligamentos seja devido a tomada de cargas elevadas na SE Santana de $69 \mathrm{KV}$ ou perda de alimentador. Portanto, após análise nesse mesmo dia dos desligamentos pelo ONS, foi verificado que o sistema apenas permanecia estável para carregamentos em patamares inferiores a $35 \mathrm{MW}$, neste sentido foi recomendado a Eletronorte que as UG02 e UG03 permanecessem operando com cerca de $35 \mathrm{MW}$, dessa forma permitindo o atendimento de cerca de 10\% da carga do Amapá de forma estável (ONS, 2020).

Contudo, seguidos de novos desligamentos da usina com interrupção de todas as cargas restabelecidas nos períodos das $14 \mathrm{~h} 49$ às $15 \mathrm{~h} 45$, das $18 \mathrm{~h} 30$ às $20 \mathrm{~h} 01$ e das $20 \mathrm{~h} 32$ às $22 \mathrm{~h} 10$ devido a variação de frequência durante o processo da tomada de carga ou perda de alimentador. O ONS a fim de evitar reincidência decidiu junto ao agente manter cargas limitas em 30 MW (ONS, 2020). Apenas no final do dia 4/11/2020 houve a estabilização do sistema, limitado a carga de $30 \mathrm{MW}$, concluindo a fase de recomposição fluente.

No dia 6/11/2020 por volta 11h16min foi autorizado a elevação da geração oriunda da UHE Coaracy Nunes do patamar de $30 \mathrm{MW}$ para $35 \mathrm{MW}$ (ONS, 2020).

Na sequência do dia 7/11/2020 por volta 4h19min foi energizado com carga o transformador TR3 230/69/13,8 kV da SE Macapá, fechando o paralelo do sistema Amapá com o SIN, atingindo o valor de 120 MW às 14h30min, restabelecendo cerca de 60 a $70 \%$ da carga do Estado do Amapá (ONS, 2020).

Após concluído restabelecimento de cerca de 60 a 70 \% das cargas foi implementado o plano de racionamento de cargas pela Companhia de Eletricidade do Amapá a fim de atender o máximo de consumidores em regime de rodizio buscando minimizar os impactos sociais provocados pelo blecaute (ONS, 2020).

A partir da disponibilidade de potência pela SE Macapá com a energização do TR3 possibilitou o atendimento de demanda em torno de $164 \mathrm{MW}$. Com isso, a CEA elaborou um plano de racionamento de energia mediante rodizio inicialmente com intervalos de 6 horas em virtude da restrição de suprimento. Após este evento iniciou-se a fase de recomposição coordenada, que a medida que o sistema garantia estabilidade o ONS autorizava liberação de suprimento a fim de adicionar mais carga.

Neste sentido, no dia 12/11/2020 com disponibilidade de 60 MW da UHE Coaracy Nunes e 123 MW do SIN viabilizou o rodizio ocorresse com intervalos de 4 horas no período diurno e a cada 3 horas no período noturno (ONS, 2020). A Companhia de Eletricidade do Amapá priorizou as cargas dos municípios de Macapá, Santana e Mazagão.

Em resumo entre o período do dia 7 a 11/11/2020 houve fornecimento de energia por 12 horas diárias enquanto no período de 12 a 13/11/2021 houve disponibilidade de 14 horas diárias.

Somente no dia 14/11/2020 as 00:00 houve um aumento de geração da UHE Coaracy Nunes no patamar de 70 MW, permanência do SIN em 123 MW. Com isso, foi possível fornecer 100\% de energia aos municípios de Santana, Tartarugalzinho, Amapá, Calçoene, Ferreira Gomes, Porto Grande, Serra do Navio, Pedra Branca, Mazagão, Pracuuba, Cutias e Itaubal até 24:00 do dia 15.11.2020.

As $03 \mathrm{~h} 31 \mathrm{~min}$ do dia 24/11/2020 foi normalizado em $100 \%$ as cargas do sistema Amapá completando assim um ciclo 
de 22 dias de restrição de suprimento para os 13 (treze) municípios do estado do Amapá.

No Quadro 2 mostra os históricos de eventos desde o dia do blecaute ocorrido no dia 3/11/2020 até o dia 15/11/2020 apresentando a evolução das cargas atendidas durante a recomposição do sistema Amapá.

Quadro 2 - Histórico de Demandas Atendidas.

\begin{tabular}{|c|l|}
\hline Data & \multicolumn{1}{c|}{ Histórico de eventos } \\
\hline $03 / 11$ & Ocorrência na SE Macapá com \\
$20: 48 \mathrm{~h}$ & $(-)$ 242 MW (Apagão) \\
\hline $04 / 11$ & Sincronização da UHE Coaracy Nunes \\
$09: 00 \mathrm{~h}$ & Em média de 15 MW (Recomposição com Cargas Prioritárias) \\
\hline $5 / 11$ & Aumento de Carga \\
$01: 00 \mathrm{~h}$ & Em média de 25 MW (Adição de Cargas Prioritárias) \\
\hline $06 / 11$ & Aumento na Geração da UHE Coaracy Nunes para 35 MW. \\
$11: 16 \mathrm{~h}$ & E aumento de carga em média de 30 MW (Adição de Cargas Prioritárias). \\
\hline $07 / 11$ & $\begin{array}{l}\text { Recuperação do TR3 da SE Macapá e adição de 120MW; } \\
\text { Aumento na geração da UHE Coaracy Nunes (44MW); } \\
\text { Totalizando em média 164 MW (Início do Rodízio nos alimentadores em 6h em 6h). }\end{array}$ \\
\hline $08 / 11$ & $\begin{array}{l}\text { Mantido os 120MW na SE Macapá; } \\
\text { Aumento na geração da UHE Coaracy Nunes (50MW); } \\
\text { Totalizando em média 170 MW (Mantido o Rodízio nos alimentadores em 6h em 6h) }\end{array}$ \\
\hline $12 / 11$ & $\begin{array}{l}\text { Aumento na disponibilidade no patamar de 123MW; } \\
\text { Aumento na geração da UHE Coaracy Nunes (60MW) } \\
\text { Totalizando em média 183 MW (Alteração do Rodízio nos alimentadores, 4h em 4h durante o dia e 3h em } \\
\text { 3h:00 h durante a noite) }\end{array}$ \\
\hline 14/11 & $\begin{array}{l}\text { Mantido os 123MW na SE Macapá; } \\
\text { Aumento na geração da UHE Coaracy Nunes (70MW) } \\
\text { Totalizando em média 193 MW (Energia 24h para as cargas prioritárias e demais municípios com exceção } \\
\text { de Macapá) }\end{array}$ \\
\hline $15 / 11$ & $\begin{array}{l}\text { Mantida as disponibilidades da SE Macapá e UHE Coaracy Nunes } \\
\text { Totalizando em média 193 MW (Energia 24h para o municípios, Macapá 24hrs das 00hrs às 12hrs, Retorno } \\
\text { do Rodízio as 19hrs) }\end{array}$ \\
\hline
\end{tabular}

Fonte: Elaborado pelos autores.

A evolução do reestabelecimento do sistema Amapá desenvolveu-se através de ação conjunta entre o ONS, Eletronorte, LMTE, ANEEL, MME e a CEA possibilitando a recomposição total do sistema em 22 dias após o incidente do dia 3 de novembro de 2020.

Caso a UG1 tivesse em condições de operação poderia disponibilizar um bloco de potência a mais, dessa forma atenderia um maior número de consumidores afetados e por mais tempo do que ocorreu durante a fase fluente da recomposição.

O TR2 de potência de 150MVA da SE Macapá encontrava-se indisponível desde 2019 em decorrência de um sinistro na bucha de $69 \mathrm{KV}$ causado por um curto circuito interno monofásico. Pode-se notar que a falta de transformador reserva neste ponto de suprimento causou ilhamento do SIN com o sistema elétrico do Amapá, impedindo a recomposição de rede elétrica. A indisponibilidade do equipamento evitaria cerca de 4 dias sem energia nos centros urbanos prioritários dos municípios de Macapá, Santana e Mazagão (ONS, 2020). E ainda, o racionamento de energia poderia ser antecipado diminuindo o número de clientes afetados.

As sucessivas interrupções no fornecimento de energia entre os dias 3 e 4/11/2020 foi provocado em virtude da dificuldade de sincronização das unidades geradoras da UHE Coaracy Nunes no processo de tomada de carga principalmente causados por variação na frequência. Observou-se que não foi possível obter dados relativos as tratativas adotados pela Eletronorte e CEA durante a fase fluente da recomposição neste período, sendo que as cargas prioritária deveriam ser previamente estabelecida nas instruções de operação do ONS, compatível com a geração, transmissão e transformação disponíveis.

Entretanto, a dificuldade de comunicação, coordenação e operação conjunta do ONS, Eletronorte e CEA impossibilitou um melhor desempenho da recomposição referente a tomada de carga. Neste sentido, no modulo 10, submodulo 10.11 trata da 
recomposição da rede de operação após perturbação onde estão as diretrizes estabelecidas para cada agente envolvido. Nota-se que a retomada de carga deve ser processada de forma gradativa com intuito de evitar eventuais oscilações de potência ou tensão que acarretariam desligamentos, que por sua vez não foi possível identificar a sequencias de energização da rede pelos dados coletados. Assim, inviabilizando analise do desempenho nesta etapa de recomposição.

Durante as etapas de recomposição as variáveis de frequência, tensão e os carregamentos devem ser controlados para garantir a estabilidade do sistema enquanto a carga é estabelecida, o que não ocorreu durante ações da Eletronorte e CEA provocando sucessivos desligamentos.

\subsection{Ações da CEA}

No dia 4/11/2020 por volta das 6h43min se inicia a fase de recomposição fluente do sistema Amapá através da Companhia de Eletricidade do Amapá em conjunto com a Eletronorte e o ONS.

Por ocasião do blecaute o sistema ficou ilhado sem a conexão com SIN dependendo apenas do suprimento da UHE Coaracy Nunes através da energização da LT 138KV que se interliga com a SE Santana. As unidades geradoras disponíveis nesta data era a UG2 e UG3 dispondo de 35 MW de potência.

Na Figura 6 mostra a demanda disponível no dia 4/11/2020 juntamente com a tomada de carga efetuada pela Companhia de Eletricidade do Amapá. Observa-se que houve diversos desligamentos ao longo do dia com intuito de estabilizar o sistema.

Figura 6 - Demanda do sistema Amapá no dia 4/11/2020.

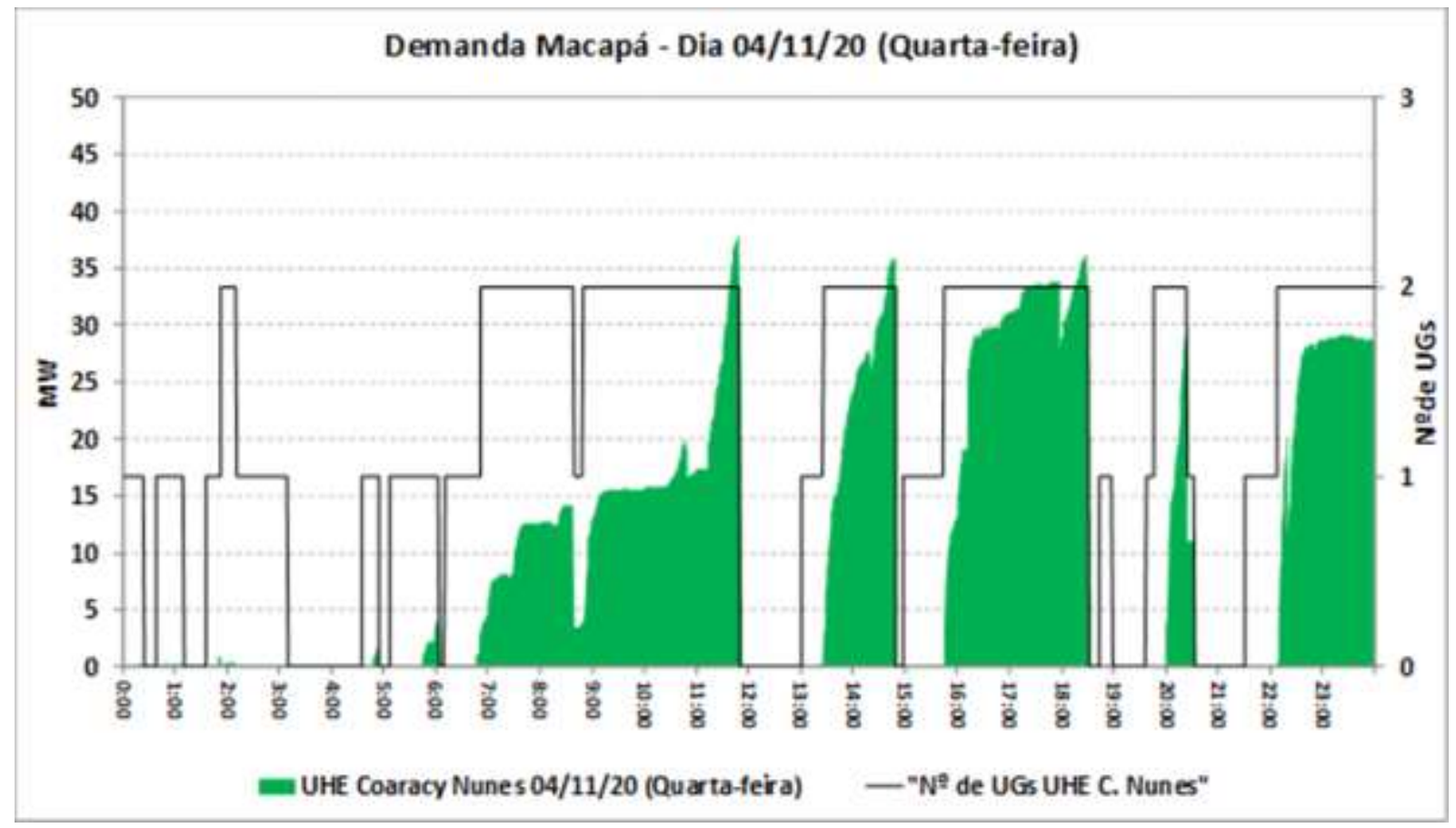

Fonte: Relatório NOS (2020).

No dia 4/11/2020, a CEA optou pela energização dos seguintes alimentadores totalizando em média 15 MW, conforme segue abaixo todos com carga reduzidas:

1) Município de Santana (SE Santana): Alimentador Matapi e Paraíso (carga reduzida);

2) Município de Macapá: SE Equatorial: Fazendinha, Setentrional, Araxá e Garden (carga reduzidas) e SE Santa Rita: Cora de Carvalho, Padre Júlio, Açucena e Presidente Vargas (cargas reduzidas). 
No dia 5/11/2020, por volta das 01:00 aumento na geração da Hidrelétrica Coaracy Nunes após autorização do ONS disponibilizando em média $25 \mathrm{MW}$, foram energizados os seguintes alimentadores por subestação:

1) Município de Santana - SE Santana: Matapi, Mazagão e Paraíso (carga reduzida);

2) Município de Macapá: SE Equatorial: Fazendinha, Setentrional, Araxá (carga reduzida); SE Santa Rita: Cora de Carvalho, Padre Júlio, Açucena, Presidente Vargas e Alvorada (carga reduzida).

3)

Figura 7 - Demanda do sistema Amapá no dia 5/11/2020.

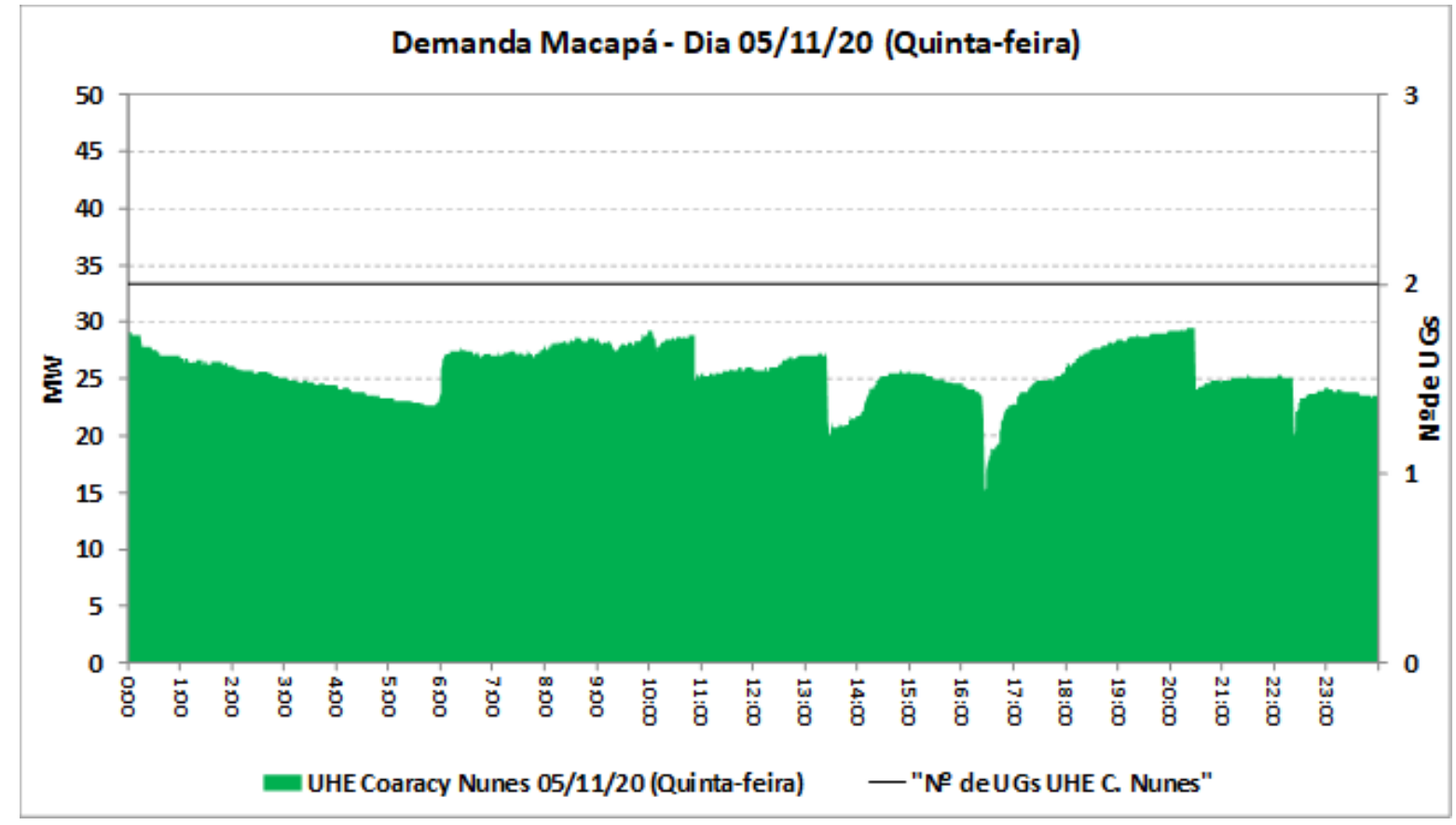

Fonte: Relatório NOS (2020).

No dia 6/11/2020, por volta das 11:06 aumento na geração da Hidrelétrica Coaracy Nunes após autorização do ONS disponibilizando em média 30MW, foram energizados os seguintes alimentadores por subestação:

1) Município de Santana e Mazagão - SE Santana: Vila Maia, Mazagão e Paraíso (carga reduzida);

2) Município de Macapá: SE Equatorial: Congós, Garden, Fazendinha, Setentrional, Araxá (carga reduzida); SE Santa Rita: Cora de Carvalho, Padre Júlio, Açucena, Presidente Vargas, Alvorada e FAB (carga reduzida). 
Figura 8 - Demanda do sistema Amapá no dia 6/11/2020.

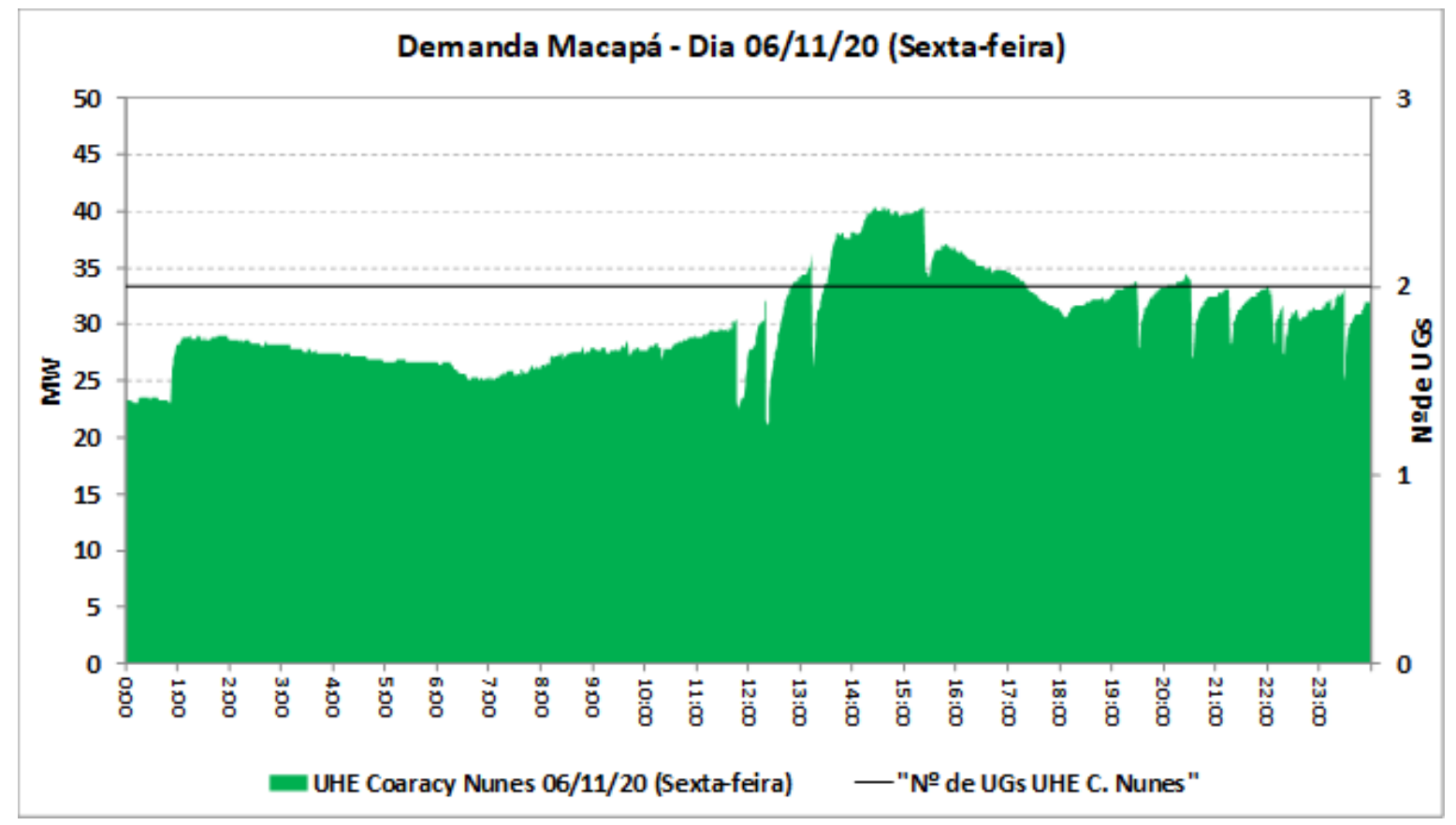

Fonte: Relatório NOS (2020).

No dia 07/11/2020 segundo o Ministério de Minas e Energia (MME), o transformador da subestação SE Macapá da LMTE/ISOLUX foi recuperado e conectado ao Sistema Interligado Nacional (SIN) às 5h05, garantindo a segurança necessária para a distribuição de energia proveniente do SIN. Com isso o sistema Amapá ficou com as seguintes gerações de energia:

1) UHE Coaracy Nunes em média $44 \mathrm{MW}$;

2) Sistema Interligado Nacional (SIN) $120 \mathrm{MW}$, sendo que foram disponibilizados aos poucos, com blocos de carga de 20MW durante ao longo do dia, com seu pico as 14:30; 
Figura 9 - Demanda do sistema Amapá no dia 7/11/2020.

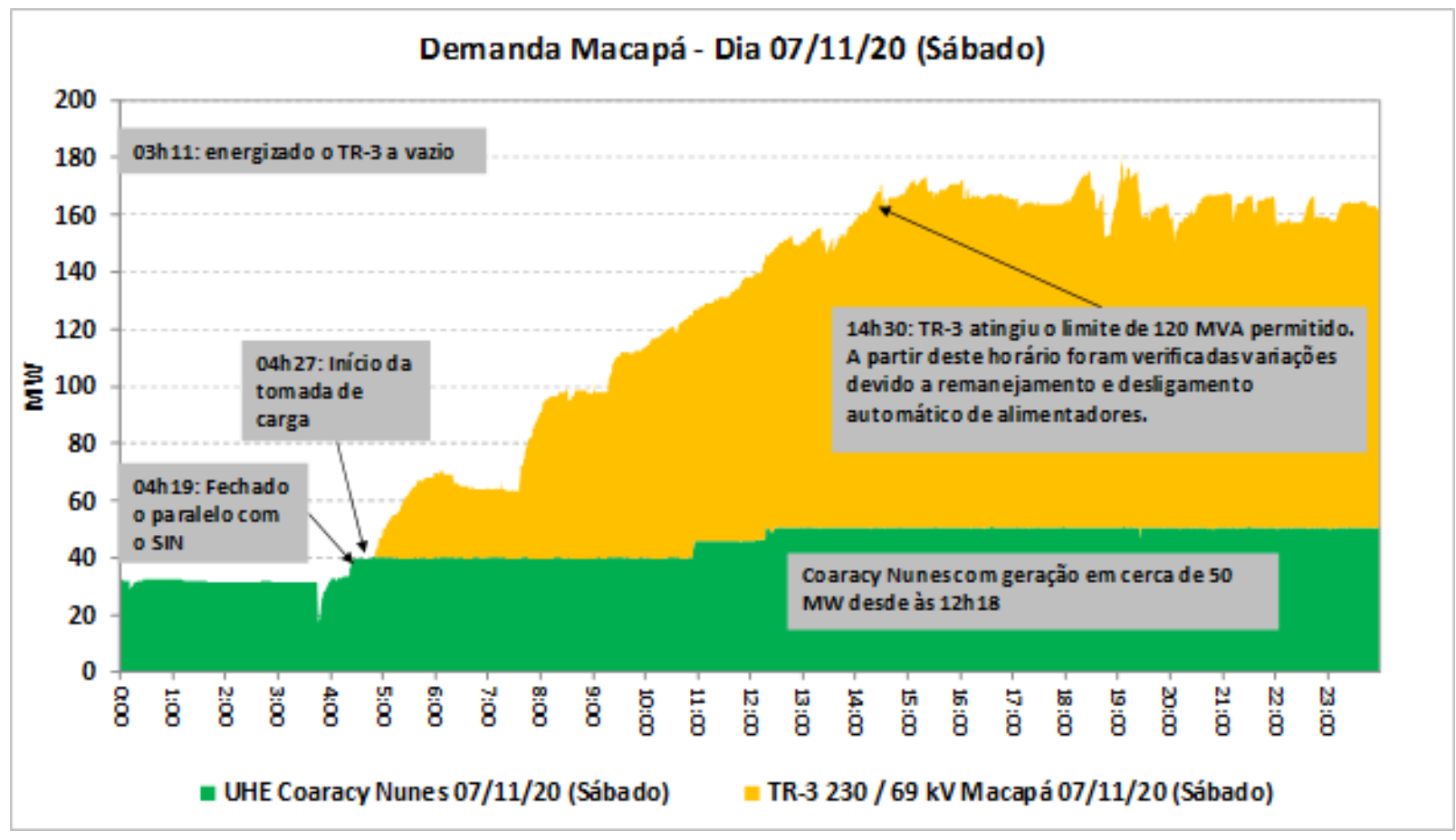

Fonte: Relatório NOS (2020).

No dia 8/11/2020, as 06:00 horas houve um aumento de geração da UHE Coaracy Nunes para 50 MW, permanência do Sistema Interligado Nacional (SIN) 120 MW, com a implementação da escala de rodízio de 6 em 6 horas, em Macapá, Santana, Tartarugalzinho, Amapá, Calçoene, Ferreira Gomes, Porto Grande, Serra do Navio, Pedra Branca, Mazagão, Pracuuba, Cutias e Itaubal. O fornecimento ocorreu de forma intercalada no intervalo de seis em seis horas para que houvesse equilibro na distribuição de energia. Os horários de referência serão de $0 \mathrm{~h}$ às $6 \mathrm{~h}, 6 \mathrm{~h}$ às $12 \mathrm{~h}, 12 \mathrm{~h}$ às $18 \mathrm{~h}$ e $18 \mathrm{~h}$ às $24 \mathrm{~h}$, com isso atendendo $60 \%$ dos consumidores atingidos pelo blecaute.

No Quadro 3 mostra o rodizio estabelecido pela CEA juntamente com os dados de carregamento dos alimentadores. Alguns alimentadores tiveram fornecimento 24 horas devido estarem ligados as unidades que prestam serviços essenciais como unidades de básicas de saúde, pronto atendimento (Hospitais, UBS’s e UPA’s), captação e distribuição de água, unidades de segurança pública, unidades de distribuição de energia elétrica, rede bancária e empresas de telecomunicação. Por questões de complexidade nas manobras, não foi possível isolar os pontos que não são denominados como essenciais. 
Quadro 3 - Racionamento de energia dia 8/11/2020.

\begin{tabular}{|c|c|c|c|c|c|}
\hline \multicolumn{6}{|c|}{ Cronograma de rodizio intervalos de 6 horas } \\
\hline \multicolumn{3}{|c|}{$\begin{array}{l}\text { INTERVALO I } \\
\text { Período: 00:00 às 06:00 horas e 12:00 as 18:00 horas }\end{array}$} & \multicolumn{3}{|c|}{$\begin{array}{c}\text { INTERVALO II } \\
\text { Período: 06:00 às 12:00 horas e 18:00 as 24:00 horas }\end{array}$} \\
\hline Subestação & Alimentador & $\begin{array}{l}\text { Carga média } \\
\text { (MVA) }\end{array}$ & Subestação & Alimentador & $\begin{array}{l}\text { Carga média } \\
\text { (MVA) }\end{array}$ \\
\hline \multirow{3}{*}{ Equatorial } & ZERÃO & 5,49 & \multirow{4}{*}{ Equatorial } & PEDRINHAS & 5,39 \\
\hline & NOVA ESPERANÇA & 6,24 & & MUCA & 7,73 \\
\hline & VALE VERDE & 7,58 & & CONGÓS & 6,80 \\
\hline Macapá II & CURIAU & 7,40 & & CAESA & 7,42 \\
\hline \multirow{3}{*}{ Macapá II } & INFRAERO & 3,83 & Equatorial & GARDEN & 4,25 \\
\hline & MARUANUM & 7,87 & \multirow{4}{*}{ Macapá II } & SÃO LAZARO & 7,98 \\
\hline & JANARY & 7,67 & & JARDIM & 7,46 \\
\hline Portuária & ICOMI & 8,31 & & PERPETUO SOCORRO & 5,28 \\
\hline \multirow{2}{*}{ Santa Rita } & EXPRESSO & 8,39 & & JULIO PEREIRA & 7,77 \\
\hline & NAÇÕES UNIDAS & 9,26 & Portuária & FORTALEZA & 7,87 \\
\hline \multirow{3}{*}{ Santana } & AP-20 & 8,29 & \multirow[t]{2}{*}{ Santa Rita } & FELICIANO & 9,28 \\
\hline & \multirow{2}{*}{ MATAPI } & \multirow{2}{*}{5,93} & & MARABAIXO & 7,87 \\
\hline & & & Santana & DUQUE & 7,73 \\
\hline \multicolumn{2}{|c|}{ Carga Rodizio Intervalo I } & 92,70 & \multicolumn{2}{|c|}{ Carga Rodizio Intervalo II } & 96,00 \\
\hline \multicolumn{6}{|c|}{ Alimentadores Energizados 24 Horas } \\
\hline Subestação & Alimentador & $\begin{array}{l}\text { Carga média } \\
\text { (MVA) }\end{array}$ & Subestação & Alimentador & $\begin{array}{l}\text { Carga média } \\
\text { (MVA) }\end{array}$ \\
\hline \multirow{5}{*}{ Santa Rita } & PRESIDENTE VARGAS & 5,28 & \multirow{3}{*}{ Equatorial } & SETENTRIONAL & 7,13 \\
\hline & AÇUCENA & 5,78 & & FAZENDINHA & 7,05 \\
\hline & FAB & 9,53 & & ARAXÁ & 7,63 \\
\hline & PADRE JULIO & 8,60 & \multirow{2}{*}{ Santana } & PARAISO & 8,18 \\
\hline & CORA DE CARVALHO & 6,13 & & VILA MAIA & 8,33 \\
\hline \multicolumn{4}{|c|}{ Total de carga que não entraram no rodizio } & \multicolumn{2}{|l|}{73,64} \\
\hline \multicolumn{4}{|c|}{ Total de Carga do Rodízio do Intervalo I } & \multicolumn{2}{|l|}{166,34} \\
\hline \multicolumn{4}{|c|}{ Total de Carga do Rodízio do Intervalo II } & \multicolumn{2}{|l|}{169,64} \\
\hline
\end{tabular}

Fonte: Autores.

No dia 12/11/2020 as 15:00 houve aumento de geração da UHE Coaracy Nunes para 60 MW e do Sistema Interligado Nacional (SIN) 123 MW. Dessa forma, foi implementado outra forma de rodízio com distinção de dias pares e ímpares e assegurando aos clientes a cada 04 horas o fornecimento de energia no horário diurno e a cada 03 horas o fornecimento de energia no horário noturno. No Quadro 4 mostra o rodizio estabelecido pela CEA a partir do dia 12/11/2020 juntamente com os dados de carregamento dos alimentadores. 
Quadro 4 - Racionamento de energia dia 12/11/2020.

\begin{tabular}{|c|c|c|c|c|c|}
\hline \multicolumn{6}{|c|}{ Cronograma de rodizio intervalos de 4 horas Diurno e 3 horas noturno } \\
\hline \multicolumn{3}{|c|}{$\begin{array}{c}\text { INTERVALO I } \\
\text { Período: } 3 \text { turno de } 4 \text { horas } \\
\end{array}$} & \multicolumn{3}{|c|}{$\begin{array}{c}\text { INTERVALO II } \\
\text { Período: } 4 \text { turno de } 3 \text { horas }\end{array}$} \\
\hline Subestação & Alimentador & $\begin{array}{c}\text { Carga média } \\
\text { (MVA) }\end{array}$ & Subestação & Alimentador & $\begin{array}{c}\text { Carga média } \\
\text { (MVA) }\end{array}$ \\
\hline \multirow{4}{*}{ Equatorial } & CONGÓS & 6,80 & \multirow{4}{*}{ Equatorial } & ZERÃO & 5,49 \\
\hline & CAESA & 7,42 & & NOVA ESPERANÇA & 6,24 \\
\hline & PEDRINHAS & 5,39 & & VALE VERDE & 7,58 \\
\hline & MUCA & 7,73 & & GARDEN & 4,25 \\
\hline \multirow{4}{*}{ Macapá II } & SÃO LAZARO & 7,98 & \multirow{5}{*}{ Macapá II } & CURIAU & 7,40 \\
\hline & JARDIM & 7,46 & & INFRAERO & 3,83 \\
\hline & \multirow{2}{*}{ PERPETUO SOCORRO } & \multirow{2}{*}{5,28} & & JANARY & 7,67 \\
\hline & & & & JULIO PEREIRA & 7,77 \\
\hline Portuária & FORTALEZA & 7,87 & & MARUANUM & 7,87 \\
\hline \multirow{3}{*}{ Santa Rita } & ALVORADA & 3,17 & \multirow{3}{*}{ Santa Rita } & EXPRESSO & 8,39 \\
\hline & \multirow{2}{*}{ FELICIANO } & \multirow{2}{*}{9,28} & & NAÇÕES UNIDAS & 9,26 \\
\hline & & & & MARABAIXO & 7,87 \\
\hline \multirow[b]{2}{*}{ Santana } & MAZAGÃO & 6,44 & \multirow[b]{2}{*}{ Santana } & AP- 20 & 8,29 \\
\hline & DUQUE & 7,73 & & MATAPI & 5,93 \\
\hline Tartarugalzinho & Todos os alimentadores & 3,00 & & & \\
\hline Amapá & Todos os alimentadores & 1,65 & & & \\
\hline Calçoene & Todos os alimentadores & 2,20 & & & \\
\hline Porto Grande & Todos os alimentadores & 9,30 & & & \\
\hline \multicolumn{2}{|c|}{ Carga Rodizio Intervalo I } & 98,70 & Carg & dizio Intervalo II & 97,84 \\
\hline \multicolumn{6}{|c|}{ Alimentadores Energizados 24 Horas } \\
\hline Subestação & Alimentador & $\begin{array}{c}\text { Carga média } \\
\text { (MVA) }\end{array}$ & Subestação & Alimentador & $\begin{array}{c}\text { Carga média } \\
\text { (MVA) }\end{array}$ \\
\hline \multirow{5}{*}{ Santa Rita } & PRESIDENTE VARGAS & 5,28 & \multirow{3}{*}{ Equatorial } & SETENTRIONAL & 7,13 \\
\hline & AÇUCENA & 5,78 & & FAZENDINHA & 7,05 \\
\hline & FAB & 9,53 & & ARAXÁ & 7,63 \\
\hline & PADRE JULIO & 8,60 & \multirow{3}{*}{ Santana } & PARAISO & 8,18 \\
\hline & CORA DE CARVALHO & 6,13 & & & \\
\hline Portuária & ICOMI & 8,31 & & VILA MAIA & 8,33 \\
\hline \multicolumn{4}{|c|}{ Total de carga que não entraram no rodizio } & \multicolumn{2}{|c|}{81,95} \\
\hline \multicolumn{4}{|c|}{ Total de Carga do Rodízio do Intervalo I } & \multicolumn{2}{|c|}{180,65} \\
\hline \multicolumn{4}{|c|}{ Total de Carga do Rodízio do Intervalo II } & \multicolumn{2}{|c|}{179,79} \\
\hline
\end{tabular}

Fonte: Elaborado pelos autores.

No Quadro 5 abaixo mostra os serviços essenciais contemplados com fornecimento de 24 horas estabelecido pela CEA como cargas prioritárias. Os tipos de serviços essenciais estão descritos no modulo 1 do PRODIST.

Quadro 5 - Serviços essenciais por alimentador.

\begin{tabular}{|c|l|}
\hline Alimentador & \multicolumn{1}{c|}{ Serviços essenciais } \\
\hline SETENTRIONAL & $\begin{array}{l}\text { Estação de Tratamento de Água, Comando Geral da PM, Centro COVID do Santa Inês e Captação de Água } \\
\text { da CAESA }\end{array}$ \\
\hline FAZENDINHA & UPA Zerão e Hospital Universitário. \\
\hline ARAXÁ & Hospital Unimed \\
\hline ICOMI & Captação de Água CAESA Santana \\
\hline PRESIDENTE VARGAS & Hospital São Camilo, Hospital da Criança, Hospital Alberto Lima e Maternidade \\
\hline AÇUCENA & UBS Lélio Silva \\
\hline FAB & HEMOAP e Poder Público em Geral e Capuchinhos \\
\hline PADRE JULIO & Hospital de Emergência e Centro de Operações da CEA \\
\hline CORA DE CARVALHO & Atendimento da CEA e Telefonia da OI \\
\hline PARAISO & Sistema de Distribuição de Âgua da CAESA no Bairro Paraíso \\
\hline VILA MAIA & Hospital de Santana e Centro de Tratamento de Água da CAESA \\
\hline
\end{tabular}

Fonte: Elaborado pelos autores. 
A estabilidade do sistema foi atingida apenas no dia 5/11/2020, ou seja, 1 (um) dia após a perturbação. Durante este intervalo a CEA e Eletronorte efetuaram diversas retomadas de cargas em virtude da atuação da proteção de subfrequência da UHE Coaracy Nunes. Durante os eventos de recomposição do sistema às 02h37min do dia 04/11/2020 houveram falhas nos equipamentos da Subestação Portuária por atuação da proteção de bloqueio 87, não aceitando a energização do Trafo PUTF501, sendo portanto necessária a intervenção local das equipe de O\&M, além de erro no serviço auxiliar da Subestação Equatorial por ocasião do sistema de VCA não comutar automaticamente a troca desta alimentação no painel do gerador de serviços emergenciais, bem como, intercorrências na Subestação Santana por defeito no comando remoto nos disjuntores, ações corrigidas pelas atuações locais das equipes de O\&M nas subestações mencionadas (ONS, 2020).

As falhas de operação dos equipamentos afetaram o desempenho na fase inicial da retomada de carga. Dos alimentadores selecionados para fornecer energia elétrica no dia 4/11/2020 apenas 2 (dois) não possuíam serviços essenciais sendo eles o Matapi e o Garden. Mesmo com cargas reduzidas a CEA poderia destinar energia para alimentadores exclusivamente prioritárias.

No momento da indisponibilidade do equipamento, observa-se o período de carga (leve, média e pesada) designado pelo ONS para tomada de ações. Entretanto, não foi possível coletar dados de sequência de energização dos alimentadores dentro da ordem de prioridades, evidenciando assim que não houve gerenciamento adequado do equilíbrio geração x carga durante ações de retomada de carga no dia 4/11/2020 provocando assim uma tomada de carga elevada forçando o desligamento da fonte supridora UHE Coaracy Nunes.

Durante as etapas de recomposição não foi possível coletar o carregamento de carga reduzida no período de 4 a 7/11/2020, dessa forma, inviabilizando analise do desempenho, contudo observa-se a necessidade de estabelecer diretrizes de gerenciamento de cargas por parte da CEA a fim de promover adequação do atendimento de cargas prioritárias, bem como estabelecer estudo para remanejamento de carga levando em consideração os blocos de cargas a serem atendidos para perda de cada equipamento de acordo com os períodos de cargas leve, média e pesada.

Pelo visto, a CEA desenvolveu o racionamento de energia considerando apenas a carga média disponibilizada pelo sistema de supervisão da Eletronorte.

Cabe ressaltar que no escopo de atender as cargas que atendem os serviços essenciais, conforme módulo 1 do PRODIST, houve maior necessidade em sanar as pendências nos equipamentos das subestações acima citadas, com exceção da Subestação Portuária que não foi atendida no primeiro momento da recomposição fluente e que estava limitada em $30 \mathrm{MW}$ em virtude dos desligamentos das unidades geradoras da UHE Coaracy Nunes, conforme observado na Tabela 3 (ONS, 2020).

\subsection{Desempenho e impacto do Esquema Regional de Alívio de Carga - ERAC durante o processo de recomposição fluente}

Conforme observado no Relatório do ONS, não foi possível avaliar o desempenho do ERAC por falta de dados da disponibilizados pela distribuidora CEA, fator este que preponderante para entender o comportamento do sistema como um todo durante os eventos da perturbação. (ONS, 2020) 
Figura 10 - ajustes estabelecidos pelo ons para o ERAC - CEA

Tabela 5 - ERAC da região de Macapá

\begin{tabular}{|c|c|c|c|c|c|c|}
\hline \multicolumn{7}{|c|}{ ERAC Macapá } \\
\hline \multirow{2}{*}{ ÁREA } & \multirow{2}{*}{ EMPRESA } & \multirow{2}{*}{$\frac{\text { o }}{\frac{5}{5}}$} & \multicolumn{2}{|c|}{$\begin{array}{c}\text { PRINCIPAL } \\
\text { (Taxa de Variação de Frequência) }\end{array}$} & \multirow{2}{*}{$\begin{array}{c}\text { RETAGUARDA } \\
\text { (Frequència } \\
\text { Absoluta) }\end{array}$} & \multirow{2}{*}{$\begin{array}{c}\text { CORTE } \\
\text { DE } \\
\text { CARGA } \\
(\%)\end{array}$} \\
\hline & & & $\begin{array}{l}\text { TAXA } \\
(\mathrm{Hz} / \mathrm{s})\end{array}$ & JANELA DE MEDIÇĀO & & \\
\hline \multirow{5}{*}{ MACAPÁ } & \multirow{5}{*}{ CEA } & 19 & 0,5 & \multirow{5}{*}{$59,70 \mathrm{~Hz}$ a $59,20 \mathrm{~Hz}$} & 58,30 & 11 \\
\hline & & 29 & 1,0 & & 58,10 & 11 \\
\hline & & 39 & 2,7 & & 57,60 & 11 \\
\hline & & 49 & 4,0 & & 57,40 & 11 \\
\hline & & 52 & - & & 57,20 & 11 \\
\hline
\end{tabular}

Fonte: Relatório NOS (2020).

Ocorre que na recomendação gerada no relatório da perturbação do dia 03 de novembro de 2020 (REC-003254/2020), o ONS solicita ao agente CEA "Encaminhar informações sobre os alimentadores e os montantes de carga que foram desligados por atuação do ERAC.", de maneira que a distribuidora por meio de sua contratada para manutenção de subestações e linhas de transmissão, realizou inspeção nos parâmetros do ERAC e observou que a função 81 - subfrequência estava desabilitada no relé modelo REF545 - ABB da SE Santa Rita, responsável pela atuação do $2^{\circ}$ e $4^{\circ}$ estágio do esquema, além de que os parâmetros (taxa de variação de frequência ou frequência absoluta) dos demais estágios estavam incompatíveis conforme vemos a seguir: (ONS, 2020).

Figura 11 - ERAC desabilitado na SE Santa Rita ( $2^{\circ}$ E $4^{\circ}$ Estágio).

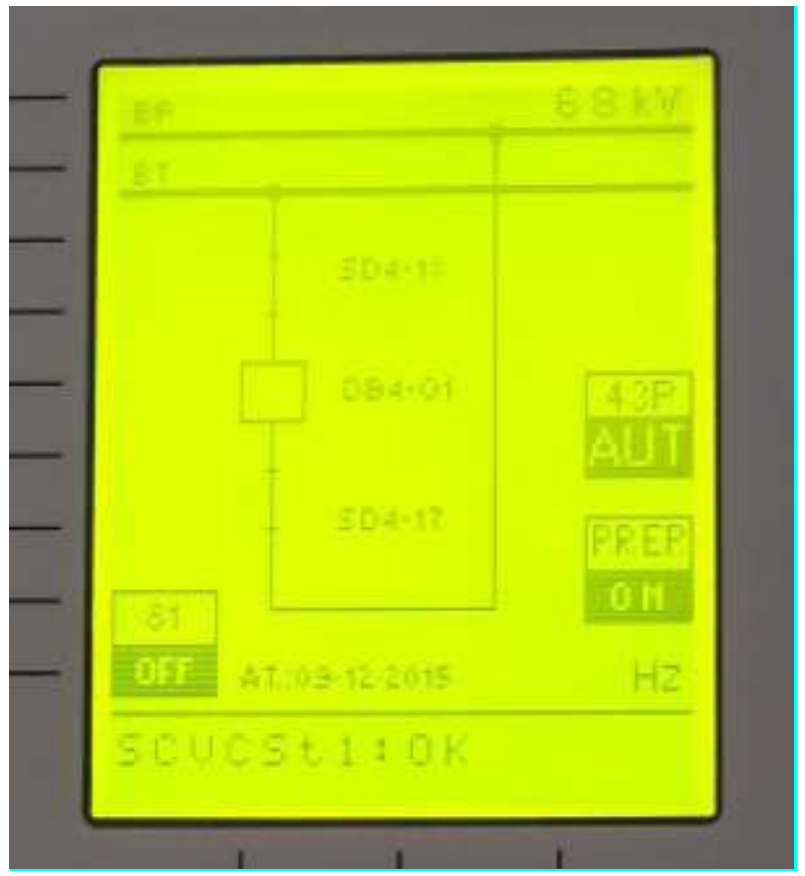

Fonte: Relatório da CEA (2020). 
Quadro 6 - Ajustes observados nos réles da SE's CEA.

\begin{tabular}{|c|c|c|c|c|}
\hline \multicolumn{5}{|c|}{ AJUSTES ERAC SE'S CEA } \\
\hline ESTÁGIO & SE & TAXA $(\mathbf{H z} / \mathbf{s})$ & JANELA DE MEDIÇÃO & INSTANTÂNEO (FREQ ABS) \\
\hline $1^{\circ}-\mathrm{ON}$ & EQUATORIAL & 0,5 & \multirow{6}{*}{$59,70 \mathrm{~Hz}$ a $59,20 \mathrm{~Hz}$} & 59,20 \\
\hline $2^{\circ}-\mathrm{OFF}$ & SANTA RITA & 1 & & 58,10 \\
\hline $3^{\circ}-\mathrm{ON}$ & EQUATORIAL & 10 & & 58,30 \\
\hline $4^{\circ}-\mathrm{OFF}$ & SANTA RITA & 4 & & 57,40 \\
\hline \multirow{2}{*}{$5^{\circ}-\mathrm{ON}$} & SANTANA & 10 & & 48,70 \\
\hline & PORTUÁRIA & - & & 58,10 \\
\hline $6^{\circ}-\mathrm{ON}$ & \multirow{2}{*}{ MACAPÁ 2} & \multirow{2}{*}{-} & \multirow{2}{*}{ - } & 56,90 \\
\hline $7^{\circ}-\mathrm{ON}$ & & & & 56,60 \\
\hline
\end{tabular}

Fonte: Relatório da CEA (2020).

É importante ressaltar que de acordo com a recomendação REC-003254/2020 e com as demais cobranças do ONS a distribuidora CEA não possuía dados do carregamento dos alimentadores de suas Subestações, sendo necessárias posteriormente ações diárias dos registros por hora da carga observada por seus operadores no supervisório (SAGE), uma vez que o sistema na distribuidora não realiza esses registros de forma automatizada. Portanto, este se mostra outro fator importante do ponto de vista da atuação do ERAC, em face do percentual de carga disponibilizado para corte não estar em conformidade com o estabelecido pelo órgão regulador, afetando, dessa maneira, os cortes seletivos nos alimentadores e por consequência o equilíbrio entre geração e carga visando manter a estabilidade do sistema durante a fase de recomposição fluente.

Considerando, ainda, que no processo de recomposição fluente por meio da UHE Coaracy Nunes a partir do dia 04/11/2021 em que houveram inúmeros desligamentos das Unidades Geradoras da referida UHE e a constatação de que o $2^{\circ}$ e $4^{\circ}$ estágios do ERAC, conforme Figura 11 estavam inoperantes na SE Santa Rita por desativação da função de subfrequência, além de que, podemos observar no quadro 6 que os parâmetros dos demais estágios (SE Equatorial e SE Santana) estavam divergentes daqueles planejados em estudos pelo ONS (figura 10) e, observando, ainda, que tanto a SE Santa Rita quanto as SE's Equatorial e Santana fazem parte integrante do processo de recomposição fluente para reestabelecimento das cargas essenciais da região metropolitana são dados importantes para o entendimento do comportamento da geração na UHE Coaracy Nunes visto no Quadro 6.

Portanto, podemos considerar como provável do ponto de vista técnico que tanto a desativação da função de proteção 81 para o $2^{\circ}$ e $4^{\circ}$ estágios do ERAC na SE Santa Rita quanto os parâmetros de atuação dos demais estágios nas subestações que participaram do processo de recomposição fluente que essas inconformidades afetaram o sistema de alívio de carga de forma negativa, influenciando no processo de recomposição fluente através da UHE Coaracy Nunes e culminando no retardando e limitação no reestabelecimento das cargas prioritárias, segunda a CEA, na média de $15 \mathrm{MM}$, enquanto que em análise prefacial o sistema poderia chegar a patamares de $35 \mathrm{MW}$ de acordo com ONS, acrescentando um ganho de aproximadamente $48 \%$ de potência disponível na fase de recomposição fluente para a distribuidora atender as cargas essenciais, além de melhorar a confiabilidade do sistema.

Nesse sentido, considerando a situação imposta pelas inconformidades observadas no ERAC da distribuidora que, por consequência, gerou instabilidade na recomposição fluente pela UHE Coaracy Nunes, verificou-se os impactos no sistema do serviço de saúde, com a necessidade em se utilizar geradores no Hospital das Clínicas (HC) e o de Emergências (HE), este último precisando, inclusive, interromper cirurgias porque ficou momentaneamente sem óleo diesel para os geradores de emergência, além dos impactos no sistema de telecomunicações que ficaram em grande parte fora de serviço e deixaram a comunicação 
precária em quase todo o estado e do sistema de captação de água que ficou comprometido com a instabilidade do sistema durante a fase de recomposição fluente e afetou a sociedade como um todo (G1 Amapá, 2020).

\section{Considerações Finais}

Este trabalho apresentou como objetivo o estudo acerca do processo de recomposição durante o estado restaurativo ocorrido no Amapá, em virtude do blecaute do dia 3 de novembro de 2020, ocasionado pelo sinistro na Subestação Macapá para avaliar o desempenho das ações realizadas pelo ONS e demais agentes envolvidos, visando apresentar possíveis soluções que poderiam reduzir os impactos causados na sociedade amapaense durante o estado restaurativo.

Neste estudo, durante a fase de coleta de dados, observou-se que a distribuidora CEA não dispõe de banco de dados acerca da maioria das informações do período em que ocorreu o blecaute e da fase de recomposição fluente, uma vez que a base histórica de registros das ações dos operadores do sistema da distribuidora durante o período supracitado é de propriedade da ELETRONORTE. Além de fatores não esclarecidos, o acesso à essas informações não foram fornecidas para a distribuidora, deixando a análise deste artigo baseada em maior parte no RAP da perturbação.

Cabe ressaltar que foram observados três pontos de melhorias que afetariam diretamente o resultado do estado restaurativo do Sistema Amapá após a perturbação na SE Macapá, qual seja a disponibilidade do TR2 (reserva) de potência de 150 MVA nesta subestação, podendo antecipar o início do rodízio entre os alimentadores das subestações de distribuidora da CEA, diminuindo em 4 dias o período sem energia nos centros urbanos prioritários dos municípios de Macapá, Santana e Mazagão, reduzindo o número de clientes afetados.

Outro ponto de melhoria avaliado foi a indisponibilidade da UG1 AMAPÁ na UHE Coaracy Nunes, que poderia disponibilizar um bloco maior de potência durante a fase de recomposição fluente, atendendo um maior número de clientes nesta fase. O outro ponto avaliado foi a habilitação do ERAC ( $2^{\circ}$ e $4^{\circ}$ estágio na SE Santa Rita) e com os demais ajustes do esquema de acordo com os estudos realizados pelo ONS, acarretando maior controle entre carga e geração, sem que houvesse o desligamento das UG's por subfrequência.

Desta feita, evidencia-se que o cenário restaurativo ao qual o Sistema Amapá ficou submetido poderia ser diferente e com impactos inferiores nos sistemas de saúde em plena pandemia de combate ao COVID-19, nos sistemas de telecomunicações, nas captações de água, nos serviços gerais e, especialmente, ao consumidor comum que não precisaria permanecer quatro dias totalmente sem energia caso os três pontos supracitados fossem corrigidos em tempo oportuno.

Como proposição para trabalhos futuros realizar estudos de planejamento da automação de sistemas de transferência de carga na rede de distribuição da subestação denominada Santa Rita com intuito de flexibilizar as contingências por falta de suprimento da rede básica.

\section{Agradecimentos}

Pró Reitoria de Pesquisa e Pós-graduação (PROPESPG) da Universidade Federal do Amapá pelo aporte financeiro.

CEA - Companhia de Eletricidade do Amapá pelo acesso aos dados.

\section{Referências}

ABRADEE (2021). Redes de Energia Elétrica. http://www. https://www.abradee.org.br/setor-eletrico/redes-de-energia-eletrica.

ABRADEE (2021). Setor elétrico. http://www.abradee.com.br/setor-eletrico/visao-geral-do-setor.

Alves, S. A. T. (2014). Analise das operações no Sistema elétrico de Média tensão Realizada pelo Centro de Controle do Sistema do Estado do Ceará. Dissertação (graduação), Universidade Federal do Ceará. 
ANEEL (2016). Agência Nacional de Energia Elétrica. Atlas de Energia elétrica do Brasil. http://www.osetoreletrico.com.br/wpcontent/uploads/2016/02/atlas_par1_cap1.pdf.

Borges, T. T.,Garcia, P.A., Carneiro JR, S., \& Pereira, J.L. (2012). Distribution System Restoration using optimal power flow. Sba: Controle e Automação Sociedade Brasileira de Automatica, 23 (6), 737-748. https://doi.org/10.1590/S0103-17592012000600007.

Brolin, L. C. (2010). Análise de planos de cortes de cargas através de métodos diretos. Dissertação (Mestrado em Engenharia elétrica), USP. https://www.teses.usp.br/teses/disponiveis/18/18154/tde-08022011-095057/publico/Leandro.pdf.

G1 AMAPÁ (18/11/2020). Apagão no Amapá: veja a cronologia da crise de energia. https://G1 Amapá.globo.com/ap/amapa/noticia/2020/11/18/apagao-noamapa-veja-a-cronologia-da-crise-de-energia-eletrica.ghtml.

G1 AMAPÁ (4/11/2020). Apagão afeta 13 dos 16 municípios do Amapá e compromete serviços de saúde e comunicação. https://G1 Amapá.globo.com/ap/amapa/noticia/2020/11/04/apagao-atinge-varios-municipios-do-amapa-e-compromete-servicos-de-comunicacao.ghtml.

G1 AMAPÁ (4/11/2020). Hospitais, trabalhadores e empresas têm transtornos e prejuízos com apagão no Amapá. https://G1 Amapá.globo.com/ap/amapa/noticia/2020/11/04/hospitais-trabalhadores-e-orgaos-publicos-sao-prejudicados-com-apagao-no-amapa.ghtml.

Idaho (n.d). University of. Principles of Sustainability - na explaration of sustainability - Charpter 6 Energy Sustainability. https://www.webpages.uidaho.edu/sustainability/chapters/ch06/ch06-p3a.asp.

Kagan, N., De Oliveira, C. C. B., \& Robba, E. J (2010). Introdução aos sistemas de distribuição de energia elétrica. Edgard Blücher.

Monticelli, A., \& Garcia, A. (2011). Introdução a Sistemas de Energia Elétrica. UNICAMP.

Mota, A. A. (2005). Metodologia computacional para avaliação da qualidade de planos de recomposição de sistemas de energia elétrica. Tese (doutorado) Universidade Estadual de Campinas, Faculdade de Engenharia Elétrica e de Computação. http://www.repositorio.unicamp.br/handle/REPOSIP/261251.

Nogueira, J. C., Rodrigues, B. D. G. D., dos Reis Fernandes, A. T., de Oliveira, W. D., \& Bezerra, U. H. (2020). Comparison between decision tree and optimal power flow techniques applied to voltage corrective control in electric systems. Itegam-Jetia, 6(21), 04-12. https://dx.doi.org/10.5935/2447-0228.20200001

Oh, J.-H.; \& Kim, J.-C. (2002). Feature extraction of fault currents associated with multi-shot reclosing scheme in power distribution system. International jornal of electrical power \& energy systems, 24 (1), 79-85. https://www.sciencedirect.com/science/article/abs/pii/S0142061501000047.

ONS (n.d). Análise da perturbação do dia 03/11/2020 às 20h48min com início nos transformadores de 230/69/13,8 kv da SE macapá, com desligamento da UHE coaracy nunes $e$ do sistema amapá. http://www.ons.org.br/AcervoDigitalDocumentosEPublicacoes/DGL-REL0016_2020\%20-\%20RAP\%2003.11.2020_20h48min_Amap\%C3\%A1_VF.pdf.

ONS (n.d). Manual de Procedimentos da Operação. $\quad$ Módulo $5.12 . \quad 2021$. http://www.ons.org.br/\%2FMPO\%2FDocumento\%20Normativo\%2F3.\%20Instru\%C3\%A7\%C3\%B5es\%20de\%20Opera\%C3\%A7\%C3\%A3o\%20-\%20SM\% 205.12\%2F3.5.\%20Gerenciamento\%20da\%20Carga\%2FIO-GC.BR.02_Rev.17.pdf.

ONS (n.d). Manual de recomposição da rede de operação após perturbação. Módulo $10 . \quad$ Submódulo 10.11. 2021. http://www.ons.org.br/\%2FProcedimentosDeRede\%2FM\%C3\%B3dulo\%2010\%2FSubm\%C3\%B3dulo\%2010.11\%2FSubm\%C3\%B3dulo\%2010.11_Rev_0.3 .pdf.

Oliveira, W. D., Vieira, J. P., Bezerra, U. H., Martins, D. A., \& Rodrigues, B. D. G. (2017). Power system security assessment for multiple contingencies using multiway decision tree. Electric Power Systems Research, 148, 264-272. https://doi.org/10.1016/j.epsr.2017.03.029

Oliveira, W. D. (2017). Avaliação da segurança de sistemas de potência para múltiplas contingências usando árvore de decisão multicaminhos. Tese (Doutorado), Universidade Federal do Pará, Instituto de Tecnologia, Programa de Pós-Graduação em Engenharia Elétrica.

Pardauil, A. C., Nascimento, T. P., Siqueira, M. R., Bezerra, U. H., \& Oliveira, W. D. (2020). Combined Approach Using Clustering-Random Forest to Evaluate Partial Discharge Patterns in Hydro Generators. Energies, 13(22), 5992. https://doi.org/10.3390/en13225992

Pestana, M. M. (2009). Recomposição de sistemas elétricos de potência, treinamento e ferramentas de apoio à recomposição. Dissertação (Mestrado), Universidade Federal de Itajubá.

Podeleski, F. S. (2017). Recomposição de Sistema de Distribuição de Energia Elétrica por Modelo de Fluxo Ótimo de Corrente. 2017. 87f. Dissertação de Mestrado do Programa de Pós-Graduação Stricto Sensu em sistemas de Infraestrutura Urbana. Pontifícia Universidade Católica de Campinas.

Souza, F. A. (2008). Detecção de falhas em sistemas de distribuição de energia elétrica usando dispositivos programáveis. Dissertação (Mestrado em Engenharia Elétrica), Programa de Pós-Graduação em Engenharia Elétrica, Universidade Estadual Paulista Júlio de Mesquita Filho. https://www.feis.unesp.br/Home/departamentos/engenhariaeletrica/pos-graduacao/228-dissertacao_fabiano_alves_de_souza.pdf.

Vaz, R. R. C. (2017). Metodologia de posicionamento de religadores e dimensionamento de rede de fibra óptica para automação de sistemas de energia. Dissertação (Mestrado) - Universidade Federal de Goiás.

Walantus, L. A. (2014). Análise Da Estabilidade De Sistema Elétrico De Potência Com Inserção De Fontes Renováveis. Dissertação (Mestrado) - Universidade Federal do Rio Grande do Sul. 